
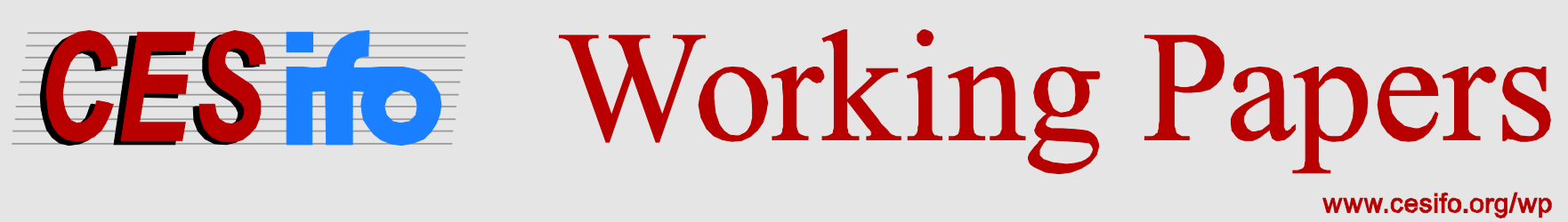

\title{
Optimal Taxation in a Habit Formation Economy
}

\author{
Sebastian Koehne \\ Moritz Kuhn
}

CESIFO WORKING PAPER NO. 4581

CATEGORY 1: PuBliC FinANCE

JANUARY 2014

An electronic version of the paper may be downloaded

- from the SSRN website:

- from the RePEc website:

- from the CESifo website:

WWw.SSRN.com

www.RePEc.org

www.CESifo-group.org/wp

\section{CESifo}




\title{
Optimal Taxation in a Habit Formation Economy
}

\begin{abstract}
We study implications of habit formation for optimal taxation. First, we show that taxation problems with habit formation can be analyzed using dynamic programming techniques. Second, we derive optimal labor and savings wedges for habit formation preferences. We show that habit formation counteracts the conventional Mirrleesian distortions and calls for subsidies to labor supply and savings. We demonstrate that the theoretical results are quantitatively important: in a stylized life-cycle model, average labor and savings wedges fall by more than one third compared to time-separable references. Third, we exploit the analogy between habit formation and durable consumption to study the taxation of durable and nondurable commodities.
\end{abstract}

JEL-Code: D820, E210, H210.

Keywords: optimal taxation, habit formation, pre-committed goods, durable goods.

Sebastian Koehne*

Institute for International Economic

Studies (IIES), Stockholm University

Sweden - 10691 Stockholm

sebastian.koehne@iies.su.se
Moritz Kuhn

University of Bonn

Department of Economics

Germany - 53113 Bonn

mokuhn@uni-bonn.de

*corresponding author

December 14, 2013

This paper is a revised and extended version of an earlier manuscript titled 'Optimal capital taxation for time-nonseparable preferences'. We are grateful to Arpad Abraham, Carlos da Costa, John Hassler, Per Krusell, Etienne Lehmann, Jean-Marie Lozachmeur, Nicola Pavoni, Pierre Pestieau, Rick van der Ploeg, and participants at various seminars and conferences for many helpful comments 


\section{Introduction}

What determines the optimal taxes on labor income and capital? Fundamental to this classic public finance question is a description of intertemporal decision making. While existing studies, following Diamond and Mirrlees (1978), have explored optimal taxation when decision makers aggregate across time in a separable way, the present paper proposes a model of decision making motivated by evidence from macroeconomics, psychology and micro data- the habit formation model. ${ }^{1}$ This model contains time-separable preferences as a special case, but allows for intertemporal complementarities in consumption.

Our paper makes three distinct contributions. First, we show that the Mirrlees taxation problem with habit formation has a recursive formulation amenable to dynamic programming techniques. Second, we characterize the components of labor and savings wedges for this problem. We show that habit formation counteracts the conventional Mirrleesian distortions. We demonstrate that the theoretical results matter quantitatively: in a stylized life-cycle example, average labor and savings wedges fall by more than one third compared to the case of timeseparable references. Third, we demonstrate the analogy between habit formation and durable consumption, and provide novel results on the taxation of durable and nondurable commodities.

Our model is a standard dynamic Mirrlees model of optimal taxation extended to the case of habit formation preferences. Agents face shocks to their abilities to generate labor income. Labor income is publicly observed, but abilities and labor supply are private information. In this environment, we characterize the solution of the social planning problem in terms of labor and savings wedges. As common in this literature, positive wedges represent implicit taxes and indicate that decentralizations of the social planning allocation must correct individual labor or savings returns downward in one way or another. ${ }^{2}$ To make the dynamic model tractable, we transform it into a dynamic programming problem by generalizing insights from the recursive contract theory literature. To the best of our knowledge, this transformation is a novel result for time-nonseparable preferences. The transformation extends beyond optimal taxation and applies to a large class of private information problems.

\footnotetext{
${ }^{1}$ See Messinis (1999) for a summary of habit formation in macroeconomics, and Frederick and Loewenstein (1999) for a review of habit formation in the empirical and behavioral economics literature.

${ }^{2}$ The decentralization of optimal allocations is not unique; compare Golosov, Kocherlakota, and Tsyvinski (2003), Kocherlakota (2005), Albanesi and Sleet (2006), Golosov and Tsyvinski (2006), Werning (2011), Gottardi and Pavoni (2011), Abraham, Koehne, and Pavoni (2013).
} 
We first study optimal labor taxation. For habit formation preferences, labor wedges are shaped by two countervailing forces. On the one hand, like in any self-selection problem with time-separable preferences, there is a motive for downward distortions to labor supply of all but the most productive type. This motive calls for positive labor wedges. On the other hand, habit formation connects present and future self-selection problems. Due to complementarity between habits and consumption, self-selection becomes easier in the future if the worker consumes a lot in the present. This habit effect calls for subsidies to labor supply for all types, and counteracts the conventional self-selection distortion. As a consequence, the 'no distortion at the top' result breaks down, and the most productive type obtains a negative labor wedge. For all other types, labor wedges can be positive or negative, depending on the importance of the habit effect compared to the conventional self-selection distortion.

We then turn to optimal savings taxation. Our decomposition of savings wedges reveals three taxation motives. First of all, savings should be taxed because the agent has a better incentive to supply labor in the next period if he starts the next period with lower wealth (wealth effect). This force is well-known from models with time-separable preferences. Second, savings should be taxed, because stimulating present consumption due to habit formation makes high consumption in the next period more attractive, which reinforces next period's labor supply incentives (immediate habit effect). Third, savings should be subsidized, because stimulating next period's consumption due to habit formation improves labor supply incentives in the remaining periods (subsequent habit effect).

Habit formation thus affects savings taxation in countervailing ways, and its impact will depend on the relative magnitude of immediate versus subsequent habit effects. In models with a finite time-horizon, incentive problems tend to aggravate over time. Therefore, relaxing future incentive problems is typically more important than relaxing immediately following ones, suggesting that habit formation may result in lower optimal savings taxes. To analyze the quantitative importance of this channel, we evaluate habit formation in a stylized numerical example with parameters according to empirical findings for the U.S. economy. The impact of habit formation on optimal savings wedges is indeed negative and sizable. Averaged over the life-cycle, optimal savings wedges of a typical worker fall by 40 percent, and optimal labor wedges by 35 percent, compared to the case of time-separable preferences. 
Finally, we explore the optimal taxation of durable and nondurable goods. Previous research has modeled durable goods as goods that are committed to before the resolution of uncertainty. A slight modification of the habit formation model allows us to propose a more explicit model of durability. We analyze optimal tax differences between durable and nondurable goods in this setup, and show how tax differences depend on complementarities between durable goods and other consumption goods. Interpreting durable consumption as housing, our findings call into question the observed tax advantages for housing wealth present in many countries.

\subsection{Related literature}

With very few exceptions, most existing studies of dynamic taxation problems work with timeseparable preferences. The contribution closest to ours is by Grochulski and Kocherlakota (2010), who explore a Mirrlees framework with time-nonseparable preferences similar to the present paper. Their focus is decentralization, and they show that social security systems (with history-dependent taxes and transfers upon retirement) can be used to implement optimal allocations when preferences are time-nonseparable. Apart from a three-period example with a negative savings wedge, they do not investigate savings or labor wedges further. Our decomposition of savings wedges shows that the subsequent habit effect is responsible for their finding. However, we also reveal that incentive problems in the immediate future create countervailing forces due to wealth and immediate habit effects. Our quantitative analysis therefore finds that, even though it is possible to construct theoretical cases where savings wedges are negative, those cases are not representative of typical taxation environments.

Another related paper is by Cremer, De Donder, Maldonado, and Pestieau (2010) and explores optimal commodity taxation in a framework with myopic habit formation. This framework gives rise to paternalistic taxation motives, as individuals do not foresee the habit formation relation when taking consumption and savings decisions. Similar effects arise when myopic habit formation is introduced into a model of retirement; see Cremer and Pestieau (2011). The present paper is different in several key aspects, as we focus on labor and savings taxation and study time-consistent decision makers that anticipate their future preferences.

Our approach towards durable commodity taxation builds on work by Cremer and Gahvari (1995a,b). We extend their setup by introducing an explicit durable good. This leads to rather 
different tax implications and clarifies the distinction between durability and pre-commitment.

Finally, the paper builds on the extensive literature on habit formation preferences. Habit formation goes back to the theory of adaptation formalized in the psychological literature by Helson (1964). Habit formation postulates that individuals compare their current consumption to a historical reference level, and derive utility both from consumption per se and from consumption growth. ${ }^{3}$ Frederick and Loewenstein (1999) review the substantial body of empirical research supporting this hypothesis. For instance, workers' self-reported well-being is often closely related to recent changes in pay, but not so much to absolute levels of pay (Clark, 1999). Ravina (2007) finds strong support for habit formation based on micro level consumption data. Moreover, habit formation has reconciled theory and evidence for several important questions in the macroeconomic literature, such as the equity premium puzzle (Abel, 1990; Constantinides, 1990; Campbell and Cochrane, 1999), the relationship between savings and growth (Ryder and Heal, 1973; Carroll, Overland, and Weil, 2000), or reactions to monetary policy shocks (Fuhrer, 2000).

\section{Model}

This section sets up a dynamic Mirrlees model of optimal taxation with habit formation preferences. The economy consists of a risk-neutral principal/planner and a unit measure of riskaverse agents facing stochastic skill shocks. Time is discrete and indexed by $t=1,2, \ldots, T$, with $T<\infty$.

\section{$2.1 \quad$ Preferences}

Agents have identical von-Neumann-Morgenstern preferences and maximize the expected value of

$$
\sum_{t=1}^{T} \beta^{t-1}\left(u\left(c_{t}, h_{t}\right)-v\left(l_{t}\right)\right)
$$

where $c_{t}, h_{t}, l_{t}$ represent the agent's consumption, habit, and labor supply in period $t$, and $\beta \in(0,1)$ is the agent's discount factor. ${ }^{4}$ Labor disutility $v: \mathbb{R}_{+} \rightarrow \mathbb{R}$ is continuous, strictly

\footnotetext{
${ }^{3}$ Besides, there is a concept of external habit formation where the reference point depends on consumption levels of a peer group; see the discussion of 'Catching up with the Joneses' in Abel (1990).

${ }^{4}$ The preferences we use are time-consistent; see Johnsen and Donaldson (1985), for example.
} 
increasing and weakly convex. Consumption utility $u: \mathbb{R}_{+}^{2} \rightarrow \mathbb{R}$ is twice continuously differentiable, strictly concave, strictly increasing in its first argument and strictly decreasing in its second argument. Consumption and habit are complements: $u_{c h}^{\prime \prime}>0$. As usual, we use subscripts to denote partial derivatives.

The complementarity assumption $u_{c h}^{\prime \prime}>0$ is standard in the habit formation literature. It holds for the widely used case of linear habit formation: $u\left(c_{t}, h_{t}\right)=\tilde{u}\left(c_{t}-\gamma h_{t}\right)$, with $\gamma \in(0,1]$ and $\tilde{u}: \mathbb{R}_{+} \rightarrow \mathbb{R}$ strictly increasing and strictly concave; compare Constantinides (1990) and Campbell and Cochrane (1999) among others. Another common specification of habit formation is the Cobb-Douglas case: $u\left(c_{t}, h_{t}\right)=\tilde{u}\left(c_{t} h_{t}^{-\gamma}\right)$, compare Abel (1990), Carroll, Overland, and Weil (2000), Fuhrer (2000), and Diaz, Pijoan-Mas, and Rios-Rull (2003). Here, $u_{c h}^{\prime \prime}>0$ holds if the coefficient of relative risk aversion of $\tilde{u}$ is bounded below by one. ${ }^{5}$

The habit level $h_{t}$ is obtained iteratively from the previous consumption and habit level:

$$
h_{t}=H\left(c_{t-1}, h_{t-1}\right), t>1, \quad h_{1} \text { given. }
$$

The function $H: \mathbb{R}_{+}^{2} \rightarrow \mathbb{R}_{+}$is continuous, strictly increasing in its first argument, weakly increasing in its second argument and weakly convex. ${ }^{6}$ The far most common example is the case of weighted averages:

$$
h_{t}=(1-\eta) c_{t-1}+\eta h_{t-1}=(1-\eta) \sum_{k=1}^{t-1} \eta^{k-1} c_{t-k}+\eta^{t-1} h_{1}
$$

where the parameter $\eta \in[0,1)$ controls the persistence of the habit process.

\subsection{Skills}

Agents differ with respect to their skills. An agent with hours $l_{t}$ and skill $\theta_{t}$ generates $y_{t}=\theta_{t} l_{t}$ units of output in period $t$. Output is publicly observable, but hours (labor input) and skill are private information.

For every $t$, let $\Theta_{t} \subset \mathbb{R}_{++}$be a finite set. Define $\Theta^{t}:=\Theta_{1} \times \cdots \times \Theta_{t}$. At the beginning of each period, a skill level $\theta_{t} \in \Theta_{t}$ is drawn for each agent. Draws are independent across agents.

\footnotetext{
${ }^{5}$ Write $\tilde{c}=c h^{-\gamma}$. Then $u_{c h}^{\prime \prime}(c, h)=\gamma h^{-\gamma-1} \tilde{u}^{\prime}(\tilde{c})\left[-\tilde{c} \tilde{u}^{\prime \prime}(\tilde{c}) / \tilde{u}^{\prime}(\tilde{c})-1\right]$.

${ }^{6}$ Convexity of $H$ is not crucial for our results. It is only imposed to ensure that life-time utility is concave in consumption.
} 
For now, we assume that draws are also independent across time. (We will relax this assumption in Section 4.1.) Hence there exist probability weights $\pi_{t}\left(\theta_{t}\right)$, with $\sum_{\theta_{t} \in \Theta_{t}} \pi_{t}\left(\theta_{t}\right)=1$, such that the probability of skill history $\theta^{t}=\left(\theta_{1}, \ldots, \theta_{t}\right) \in \Theta^{t}$ is given by $\Pi^{t}\left(\theta^{t}\right)=\pi_{1}\left(\theta_{1}\right) \cdots \pi_{t}\left(\theta_{t}\right)$. Without loss of generality, we assume $\pi_{t}\left(\theta_{t}\right)>0$ for all $\theta_{t} \in \Theta_{t}$.

We denote the expectation operator with respect to the unconditional distribution of skill histories $\theta^{T}$ by $\mathbb{E}[\cdot]$. As usual, the notation $\mathbb{E}_{t}[\cdot]:=\mathbb{E}\left[\cdot \mid \theta^{t}\right]$ represents expectations conditional on the time- $t$ history $\theta^{t}$.

\subsection{Social planner}

We set up the social planning problem in its dual form: the social planner minimizes the costs of delivering a given level of ex-ante welfare to the agents. Future costs are discounted with factor $q<1$. Equivalently, the planner has access to a linear savings technology that transforms $q$ units of date-t output into 1 unit of output at date $t+1$. It would not be difficult to endogenize the return of the savings technology by introducing an explicit production function that depends on capital and labor. Yet, this would complicate the notation and generate no additional insights.

\subsection{Allocations}

Let $\underline{c}, \bar{c}, \underline{y}, \bar{y} \in \mathbb{R}_{++}$with $\underline{c}<\bar{c}$ and $\underline{y}<\bar{y}$. An allocation is a sequence $(\mathbf{c}, \mathbf{y})=\left(c_{t}, y_{t}\right)_{t=1, \ldots, T}$ of consumption plans $c_{t}: \Theta^{t} \rightarrow[\underline{c}, \bar{c}]$ and output plans $y_{t}: \Theta^{t} \rightarrow[\underline{y}, \bar{y}]$. A consumption allocation, combined with a fixed initial habit $h_{1}$, generates a unique sequence of habit levels $\left(h_{t}\left(\theta^{t-1}\right)\right)_{t=1, \ldots, T}$ according to equation (2).

A reporting strategy is a sequence $\sigma=\left(\sigma_{t}\right)_{t=1, \ldots, T}$ of mappings $\sigma_{t}: \Theta^{t} \rightarrow \Theta_{t}$. Denote the set of all reporting strategies by $\Sigma$ and set $\sigma^{t}\left(\theta^{t}\right):=\left(\sigma_{1}\left(\theta^{1}\right), \ldots, \sigma_{t}\left(\theta^{t}\right)\right)$. At the beginning of every period, the planner allocates consumption and output according to the history of reported skills. Reporting strategy $\sigma \in \Sigma$ yields ex-ante expected utility according to:

$$
\begin{aligned}
& w_{1}\left(\mathbf{c} \circ \sigma, \mathbf{y} \circ \sigma ; h_{1}\right) \\
& :=\sum_{t=1}^{T} \sum_{\theta^{t} \in \Theta^{t}} \beta^{t-1}\left[u\left(c_{t}\left(\sigma^{t}\left(\theta^{t}\right)\right), h_{t}\left(\sigma^{t-1}\left(\theta^{t-1}\right)\right)\right)-v\left(\frac{y_{t}\left(\sigma^{t}\left(\theta^{t}\right)\right)}{\theta_{t}}\right)\right] \Pi^{t}\left(\theta^{t}\right)
\end{aligned}
$$

Since skills are privately observed, the planner needs to ensure that all agents reveal their 
information truthfully. An allocation that satisfies the truth-telling constraint

$$
w_{1}\left(\mathbf{c}, \mathbf{y} ; h_{1}\right) \geq w_{1}\left(\mathbf{c} \circ \sigma, \mathbf{y} \circ \sigma ; h_{1}\right) \quad \forall \sigma \in \Sigma
$$

is called incentive compatible.

\subsection{Optimal allocations}

The social planner seeks to provide a given level $W_{1}$ of ex-ante welfare at minimal costs. Hence, an allocation $(\mathbf{c}, \mathbf{y})$ is called optimal if it solves the following problem:

$$
\begin{aligned}
C_{1}\left(W_{1}, h_{1}\right):=\min _{\mathbf{c}, \mathbf{y}} \sum_{t=1}^{T} \sum_{\theta^{t} \in \Theta^{t}} q^{t-1}\left[c_{t}\left(\theta^{t}\right)-y_{t}\left(\theta^{t}\right)\right] \Pi^{t}\left(\theta^{t}\right) \\
\text { s.t. } \\
w_{1}\left(\mathbf{c}, \mathbf{y} ; h_{1}\right) \geq w_{1}\left(\mathbf{c} \circ \sigma, \mathbf{y} \circ \sigma ; h_{1}\right) \quad \forall \sigma \in \Sigma \\
w_{1}\left(\mathbf{c}, \mathbf{y} ; h_{1}\right)=W_{1}
\end{aligned}
$$

\section{Recursive formulation}

This section rewrites the multi-period optimal taxation problem from Section 2 as a dynamic programming problem with two state variables: promised utility and the agent's habit level. Our results extend findings from Spear and Srivastava (1987) and Phelan and Townsend (1991) to the class of habit formation preferences.

The key step for the recursive formulation is to write the incentive compatibility constraint (7) in sequential form. First we introduce some notation. Given allocation $(\mathbf{c}, \mathbf{y})$ and a history $\theta^{t}$, the continuation allocation $\left(c_{t+1}^{T}\left(\theta^{t}\right), y_{t+1}^{T}\left(\theta^{t}\right)\right)$ is defined as the restriction of plans $\left(c_{s}, y_{s}\right)_{s=t+1, \ldots, T}$ to those histories $\theta^{t+1}, \ldots, \theta^{T}$ that succeed $\theta^{t}$. The continuation utility associated with $\left(c_{t+1}^{T}\left(\theta^{t}\right), y_{t+1}^{T}\left(\theta^{t}\right)\right)$ is defined as:

$$
\begin{aligned}
& w_{t+1}\left(c_{t+1}^{T}\left(\theta^{t}\right), y_{t+1}^{T}\left(\theta^{t}\right) ; h_{t+1}\left(\theta^{t}\right)\right) \\
& :=\sum_{s=t+1}^{T} \sum_{\theta^{s} \in \Theta^{s}} \beta^{s-t-1}\left[u\left(c_{s}\left(\theta^{s}\right), h_{s}\left(\theta^{s-1}\right)\right)-v\left(\frac{y_{s}\left(\theta^{s}\right)}{\theta_{s}}\right)\right] \Pi^{s}\left(\theta^{s} \mid \theta^{t}\right)
\end{aligned}
$$


Note that, in contrast to the time-separable case, continuation utility $w_{t+1}$ does not only depend on the continuation allocation, but also on the consumption history $c^{t}\left(\theta^{t}\right)$ as summarized by the one-dimensional statistic $h_{t+1}\left(\theta^{t}\right)$.

The following result transforms the incentive compatibility constraint into a sequence of temporary constraints. For the proof of Lemma 1 and all other proofs see Appendix A.

Lemma 1 (One-shot deviation principle). Allocation $(\mathbf{c}, \mathbf{y})$ is incentive compatible if and only if it satisfies the following condition for all $t$ and all $\theta^{t} \in \Theta^{t}, \hat{\theta} \in \Theta_{t}$ :

$$
\begin{aligned}
& u\left(c_{t}\left(\theta^{t}\right), h_{t}\left(\theta^{t-1}\right)\right)-v\left(\frac{y_{t}\left(\theta^{t}\right)}{\theta_{t}}\right)+\beta w_{t+1}\left(c_{t+1}^{T}\left(\theta^{t}\right), y_{t+1}^{T}\left(\theta^{t}\right) ; H\left(c_{t}\left(\theta^{t}\right), h_{t}\left(\theta^{t-1}\right)\right)\right) \\
& \geq u\left(c_{t}\left(\theta^{t-1}, \hat{\theta}\right), h_{t}\left(\theta^{t-1}\right)\right)-v\left(\frac{y_{t}\left(\theta^{t-1}, \hat{\theta}\right)}{\theta_{t}}\right) \\
& \quad+\beta w_{t+1}\left(c_{t+1}^{T}\left(\theta^{t-1}, \hat{\theta}\right), y_{t+1}^{T}\left(\theta^{t-1}, \hat{\theta}\right), H\left(c_{t}\left(\theta^{t-1}, \hat{\theta}\right), h_{t}\left(\theta^{t-1}\right)\right)\right)
\end{aligned}
$$

Condition (10) states that it is not profitable to misreport one's skill in period $t$ and report the truth in all periods thereafter. If this condition holds for all periods and all possible histories, Lemma 1 shows that no reporting strategy (potentially involving deviations in multiple timeperiods) does better than truth-telling.

Based on definition (9), the promise keeping constraint (8) can be written as:

$$
W_{1}=\sum_{\theta_{1} \in \Theta_{1}}\left[u\left(c_{1}\left(\theta_{1}\right), h_{1}\right)-v\left(\frac{y_{1}\left(\theta_{1}\right)}{\theta_{1}}\right)+\beta w_{2}\left(c_{2}^{T}\left(\theta_{1}\right), y_{2}^{T}\left(\theta_{1}\right) ; H\left(c_{1}\left(\theta_{1}\right), h_{1}\right)\right)\right] \pi_{1}\left(\theta_{1}\right)
$$

Similarly, for periods $t>1$ definition (9) is equivalent to:

$$
\begin{aligned}
w_{t} & \left(c_{t}^{T}\left(\theta^{t-1}\right), y_{t}^{T}\left(\theta^{t-1}\right) ; h_{t}\left(\theta^{t-1}\right)\right) \\
= & \sum_{\theta_{t} \in \Theta_{t}}\left[u\left(c_{t}\left(\theta^{t-1}, \theta_{t}\right), h_{t}\left(\theta^{t-1}\right)\right)-v\left(\frac{y_{t}\left(\theta^{t-1}, \theta_{t}\right)}{\theta_{t}}\right)\right] \pi_{t}\left(\theta_{t}\right) \\
& +\beta \sum_{\theta_{t} \in \Theta_{t}} w_{t+1}\left(c_{t+1}^{T}\left(\theta^{t-1}, \theta_{t}\right), y_{t+1}^{T}\left(\theta^{t-1}, \theta_{t}\right) ; H\left(c_{t}\left(\theta^{t-1}, \theta_{t}\right), h_{t}\left(\theta^{t-1}\right)\right)\right) \pi_{t}\left(\theta_{t}\right)
\end{aligned}
$$

In summary, the incentive compatibility constraint (7) of the social planner problem is equivalent to the sequence of temporary constraints (10), while the promise keeping constraint (8) is equivalent to condition (11) in combination with the sequence (12) of constraints for 
continuation utilities $w_{t}, t>1$.

We define $\operatorname{dom}_{t}(h)$ to be the set of time- $t$ continuation utilities $W$ with the property that, given time- $t$ habit level $h_{t}=h$, there exists an incentive compatible allocation $\left(c_{t}^{T}, y_{t}^{T}\right)$ that satisfies the boundary constraints $\bar{c} \geq c_{s} \geq \underline{c}$ and $\bar{y} \geq y_{s} \geq \underline{y}$ for all $T \geq s \geq t$, and generates utility

$$
\mathbb{E}\left[\sum_{s=t}^{T} \beta^{s-1}\left(u\left(c_{s}, h_{s}\right)-v\left(y_{s} / \theta_{s}\right)\right)\right]=W, \quad \text { where } h_{t}=h, h_{s}=H\left(c_{s-1}, h_{s-1}\right) \text { for } s>t
$$

Given the structure of our problem, we can find a closed form expression for $\operatorname{dom}_{t}(h)$.

Lemma 2 (Domain restriction). For any $h \in \mathbb{R}_{+}$and $1 \leq t \leq T$, the set $\operatorname{dom}_{t}(h)$ is a nonempty, compact interval. Setting $\bar{h}_{t}=\underline{h}_{t}=h$, and $\bar{h}_{s}=H\left(\bar{c}, \bar{h}_{s-1}\right), \underline{h}_{s}=H\left(\underline{c}, \underline{h}_{s-1}\right), s>t$, the interval bounds are given by

$$
\begin{aligned}
& \max \left(\operatorname{dom}_{t}(h)\right)=\sum_{s=t}^{T} \beta^{s-1}\left(u\left(\bar{c}, \bar{h}_{s}\right)-\sum_{\theta \in \Theta_{s}} \pi_{s}(\theta) v(\underline{y} / \theta)\right) \\
& \min \left(\operatorname{dom}_{t}(h)\right)=\sum_{s=t}^{T} \beta^{s-1}\left(u\left(\underline{c}, \underline{h}_{s}\right)-\sum_{\theta \in \Theta_{s}} \pi_{s}(\theta) v(\bar{y} / \theta)\right) .
\end{aligned}
$$

Lemma 2 states that the maximum incentive-compatible continuation utility is obtained by setting consumption to the upper bound $\bar{c}$ and output to the lower bound $\underline{y}$ for all realizations and all periods. The associated habit path is denoted $\bar{h}_{s}, T \geq s \geq t$. Similarly, the minimum incentive-compatible continuation utility is obtained by setting consumption to $\underline{c}$ and output to $\bar{y}$ for all realizations and all periods.

Since the constraint set can be given the sequential form (10), (11), (12), the social planner problem is a standard dynamic programming problem. The Principle of Optimality for this problem is summarized as follows.

Proposition 1 (Recursive formulation). Let $W_{1} \in \operatorname{dom}_{1}\left(h_{1}\right)$. The value $C_{1}\left(W_{1}, h_{1}\right)$ of the social planner problem (6) can be computed by backward induction using the following equation 
for all $t$ (with the convention $C_{T+1}=0$ and $W^{\prime}=0$ at $t=T$ ):

$$
\begin{aligned}
& C_{t}(W, h)=\min _{c(\theta), y(\theta), W^{\prime}(\theta)} \sum_{\theta \in \Theta_{t}} \pi_{t}(\theta)\left[c(\theta)-y(\theta)+q C_{t+1}\left(W^{\prime}(\theta), H(c(\theta), h)\right)\right] \\
& \quad \text { s.t. } \\
& u(c(\theta), h)-v(y(\theta) / \theta)+\beta W^{\prime}(\theta) \geq u\left(c\left(\theta^{\prime}\right), h\right)-v\left(y\left(\theta^{\prime}\right) / \theta\right)+\beta W^{\prime}\left(\theta^{\prime}\right) \quad \forall \theta, \theta^{\prime} \in \Theta_{t} \\
& \sum_{\theta \in \Theta_{t}} \pi_{t}(\theta)\left[u(c(\theta), h)-v(y(\theta) / \theta)+\beta W^{\prime}(\theta)\right]=W \\
& W^{\prime}(\theta) \in \operatorname{dom}_{t}(H(c(\theta), h)), \bar{c} \geq c(\theta) \geq \underline{c}, \bar{y} \geq y(\theta) \geq \underline{y} \quad \forall \theta \in \Theta_{t}
\end{aligned}
$$

Moreover, plans $\left(c_{t}, y_{t}\right)_{t=1, \ldots, T}$ that solve the sequence of problems (16) constitute an optimal allocation. Conversely, any optimal allocation solves the sequence of problems (16).

Proposition 1 separates the social planner problem (6) into a sequence of simpler problems, where the planner at every point in time determines current consumption, current output, and continuation utility as a function of the current skill. Choices are constrained by the temporary incentive compatibility constraint (17), the promise keeping constraint (18), and the boundary constraint (19). The only difference to the familiar recursive formulation for incentive problems with time-separable preferences is that the agent's habit level becomes an additional state variable.

\section{Labor and savings wedges}

This section derives the wedges (tax distortions) imposed by optimal allocations. As is well known in the dynamic public finance literature, the decentralization of optimal allocations is not unique. Hence, the robust insights from the present analysis are not about explicit tax instruments, but about wedges.

In order to define labor and savings wedges, we first examine the agent's marginal utility of consumption. With habit formation, current consumption influences future habit levels. Given a consumption history $\left(c_{1}, \ldots, c_{T}\right)$, the marginal utility of consuming at date $t$ is given by

$$
\tilde{U}_{t}:=u_{c}^{\prime}\left(c_{t}, h_{t}\right)+\sum_{s=t+1}^{T} \beta^{s-t} u_{h}^{\prime}\left(c_{s}, h_{s}\right) \frac{\partial h_{s}}{\partial c_{t}} .
$$


If consumption in periods $t+1, \ldots, T$ is uncertain from the point of view of period $t$, marginal consumption utility becomes a random variable. We write $U_{t}:=\mathbb{E}_{t}\left[\tilde{U}_{t}\right]$ for the expectation of this random variable conditional on date- $t$ information.

Given an allocation $(\mathbf{c}, \mathbf{y})$, define the labor wedge in period $t$

$$
\tau_{y, t}:=1-\frac{v^{\prime}\left(y_{t} / \theta_{t}\right)}{\theta_{t} U_{t}}
$$

and the savings wedge in period $t$

$$
\tau_{s, t}:=1-\frac{q U_{t}}{\beta \mathbb{E}_{t}\left[U_{t+1}\right]}
$$

Note that $\tau_{y, t}$ and $\tau_{s, t}$ are random variables that depend on the date- $t$ history $\theta^{t}$, even though we have omitted this argument for notational convenience. Apart from the fact that habit formation changes the formula for marginal consumption utility $U_{t}$, the above definitions are standard. The labor wedge is the implicit tax rate that equates the agent's marginal rate of substitution between consumption and leisure to the after-tax income of an additional unit of labor supply. Similarly, the savings wedge is the implicit tax rate that aligns the agent's marginal rate of intertemporal substitution with the relative price of future consumption.

In its general form, our model is not very tractable for theoretical analysis. We therefore maintain the following assumptions.

Assumption 1. Only local downward incentive constraints are binding.

Assumption 1 is a discrete version of the well-known envelope condition; see Mirrlees (1971). This assumption is standard in the optimal taxation literature.

Assumption 2. Skill realizations are binary: $\Theta_{t}=\left\{\underline{\theta}_{t}, \bar{\theta}_{t}\right\}$, with $\underline{\theta}_{t} \leq \bar{\theta}_{t}$.

Assumption 3. Habits are short-lived: $h_{t}=c_{t-1}$.

Assumptions 2 and 3 facilitate the exposition, but are not essential for our results. Relaxations of these assumptions are discussed in Section 4.1. Note that Assumption 2 is a common simplification for discrete income taxation problems; see Feldstein (1973), Stern (1982), or Stiglitz (1982), for example.

Assumption 4. The boundary constraints $\bar{c} \geq c_{t} \geq \underline{c}$ and $\bar{y} \geq y_{t} \geq \underline{y}$ are slack. 
Assumption 4 is hardly restrictive. The time-horizon and the skill set are finite, hence (given appropriate Inada conditions) we can find bounds for the allocation variables that are not binding.

Under Assumptions 1-4, the recursive formulation of the optimal taxation problems takes the following form for $t<T$ :

$$
\begin{aligned}
& C_{t}\left(W_{t}, h_{t}\right)=\min _{\left(c_{t}(\theta), y_{t}(\theta), W_{t+1}(\theta)\right)} \sum_{\theta \in\left\{\underline{\theta}_{t}, \bar{\theta}_{t}\right\}} \pi_{t}(\theta)\left[c_{t}(\theta)-y_{t}(\theta)+q C_{t+1}\left(W_{t+1}(\theta), c_{t}(\theta)\right)\right] \\
& \text { s.t. } \\
& u\left(c_{t}\left(\bar{\theta}_{t}\right), h_{t}\right)-v\left(y_{t}\left(\bar{\theta}_{t}\right) / \bar{\theta}_{t}\right)+\beta W_{t+1}\left(\bar{\theta}_{t}\right) \geq u\left(c_{t}\left(\underline{\theta}_{t}\right), h_{t}\right)-v\left(y_{t}\left(\underline{\theta}_{t}\right) / \bar{\theta}_{t}\right)+\beta W_{t+1}\left(\underline{\theta}_{t}\right) \\
& \sum_{\theta \in\left\{\underline{\theta}_{t}, \bar{\theta}_{t}\right\}} \pi_{t}(\theta)\left[u\left(c_{t}(\theta), h_{t}\right)-v\left(y_{t}(\theta) / \theta\right)+\beta W_{t+1}(\theta)\right]=W_{t}
\end{aligned}
$$

For $t=T$, equations (23), (24), (25) hold with $C_{T+1}=W_{T+1}=0$. Note that, due to Assumption 1, only the incentive compatibility constraint for the high-skilled agent is imposed.

In what follows, we fix the period- $t$ state vector $\left(W_{t}, h_{t}\right)$. Equivalently, we fix the associated skill history $\theta^{t-1}$. We denote the Lagrange multiplier for the incentive compatibility constraint (24) by $\mu_{t}$, and the multiplier for the promise keeping constraint (25) by $\lambda_{t}$.

We begin our analysis with the following preliminary insight.

Proposition 2 (Homogeneous skills). Let (c, $\mathbf{y})$ be an optimal allocation and suppose $\underline{\theta}_{t}=\bar{\theta}_{t}$ for $t \geq t_{0}$. Then the labor and savings wedges are zero: $\tau_{y, t}=\tau_{s, t}=0$ for $t \geq t_{0}$.

Proposition 2 implies that tax distortions in our model are entirely due to incentive problems, exactly like in the case of time-separable preferences. Thus, habit formation does not create a direct taxation motive. As we will see now, habit formation creates an important indirect taxation motive, because it changes the structure of the incentive problem.

Proposition 3 (Labor wedges). Let $(\mathbf{c}, \mathbf{y})$ be an optimal allocation. For each history $\theta^{t-1}, t<$ $T$, there exist numbers $A_{t}\left(\underline{\theta}_{t}\right), B_{t}\left(\underline{\theta}_{t}\right), B_{t}\left(\bar{\theta}_{t}\right) \geq 0$, and Lagrange multipliers $\mu_{t}, \mu_{t+1}\left(\underline{\theta}_{t}\right), \mu_{t+1}\left(\bar{\theta}_{t}\right) \geq$ 0 associated with the incentive compatibility constraints in periods $t$ and $t+1$ such that:

$$
\begin{aligned}
\tau_{y, t}\left(\theta^{t-1}, \bar{\theta}_{t}\right) & =-\mu_{t+1}\left(\bar{\theta}_{t}\right) B_{t}\left(\bar{\theta}_{t}\right) \leq 0, \\
\tau_{y, t}\left(\theta^{t-1}, \underline{\theta}_{t}\right) & =\mu_{t} A_{t}\left(\underline{\theta}_{t}\right)-\mu_{t+1}\left(\underline{\theta}_{t}\right) B_{t}\left(\underline{\theta}_{t}\right) \gtrless 0
\end{aligned}
$$


For $t=T$, equations (26) and (27) hold with $\mu_{t+1}\left(\underline{\theta}_{t}\right), \mu_{t+1}\left(\bar{\theta}_{t}\right)$ replaced by zero. Finally, in the limit case of time-separable preferences $\left(u_{h}=0\right)$, we have $B_{t}\left(\underline{\theta}_{t}\right)=B_{t}\left(\bar{\theta}_{t}\right)=0$.

For time-separable preference, Proposition 3 states that the labor wedge of the high-skilled worker is zero ('no distortion at the top'). The low-skilled worker faces the positive labor wedge $\mu_{t} A_{t}$. As usual in self-selection problems, this downward distortion is efficient, because it reduces the incentive of the high-skilled worker to pretend being low-skilled.

With habit formation, the same self-selection distortion continues to apply. In addition, there is a motive for subsidizing the labor supply of high-skilled as well as low-skilled workers, captured by the terms $\mu_{t+1} B_{t}$. As the Lagrange multiplier $\mu_{t+1}$ indicates, this motive is due to the incentive problem in period $t+1$. The proof of Proposition 3 reveals that $B_{t}$ can be expressed as

$$
B_{t}=b_{t}\left[u_{h}^{\prime}\left(\bar{c}_{t+1}, h_{t+1}\right)-u_{h}^{\prime}\left(\underline{c}_{t+1}, h_{t+1}\right)\right]=b_{t} u_{c h}^{\prime \prime}\left(\xi, h_{t+1}\right)\left[\bar{c}_{t+1}-\underline{c}_{t+1}\right]
$$

where $b_{t}=b_{t}\left(\theta^{t}\right)$ is a strictly positive number, while $h_{t+1}=h_{t+1}\left(\theta^{t}\right)$ and $\bar{c}_{t+1}=c_{t+1}\left(\theta^{t}, \bar{\theta}_{t+1}\right)$, $\underline{c}_{t+1}=c_{t+1}\left(\theta^{t}, \underline{\theta}_{t+1}\right)$ are the habit and consumption levels in period $t+1$, and $\xi=\xi\left(\theta^{t}\right)$ is some number between $\underline{c}_{t+1}$ and $\bar{c}_{t+1}$. Since habit and consumption are by assumption complements, $B_{t}$ is positive and enters negatively into the labor wedge. The intuition for this is as follows. A low labor wedge encourages work at date $t$. This increases date- $t$ consumption and results in a higher habit level $h_{t+1}$ at date $t+1$. Due to complementarity, the difference between the utility of a high-skilled worker $u\left(\bar{c}_{t+1}, h_{t+1}\right)$ and a low-skilled worker $u\left(\underline{c}_{t+1}, h_{t+1}\right)$ increases. This effect is socially desirable because it facilitates self-selection at $t+1$.

At a more general level, Proposition 3 shows that optimal intra-period distortions take into account intertemporal preference dependencies. Since high habit levels are helpful for future incentive problems, this generates a motive for subsidizing labor across all skill types - the habit effect $B_{t}$. As a consequence, the labor wedge for high-skilled agents is negative ('subsidies at the top'), while the labor wedge for low-skilled agents consists of the standard taxation motive for current incentive provision $A_{t}$ minus the habit effect $B_{t}$.

We now turn to the analysis of savings wedges. For time-separable preferences, savings wedges can be analyzed by variational arguments that perturb optimal allocations in two ad- 
jacent time-periods. The result is the seminal Inverse Euler equation. ${ }^{7}$ Unfortunately, this approach does not extend to the class of habit formation preferences. The key problem is that consumption at any given point in time affects future habit levels. Therefore, the contribution of consumption in periods $t$ and $t+1$ to the worker's life-time utility depends on subsequent consumption levels, and hence on subsequent skill realizations. It is thus impossible to find a consumption perturbation that is incentive-neutral and uses only information from periods $t$ and $t+1$ (unless $t=T-1$ ); see Grochulski and Kocherlakota (2010).

The Lagrangian techniques adopted in this paper deliver insights on savings wedges even for the habit formation case. The result is as follows.

Proposition 4 (Savings wedges). Let (c, $\mathbf{y})$ be an optimal allocation. For each history $\theta^{t}, t<$ $T-1$, there exist numbers $D_{t}, E_{t}, F_{t}\left(\theta_{t+1}\right) \geq 0$, and Lagrange multipliers $\mu_{t+1}, \mu_{t+2}\left(\theta_{t+1}\right) \geq 0$ associated with the incentive compatibility constraints in periods $t+1$ and $t+2$ such that:

$$
\tau_{s, t}\left(\theta^{t}\right)=\mu_{t+1} D_{t}+\mu_{t+1} E_{t}-\sum_{\underline{\theta}_{t+1}, \bar{\theta}_{t+1}} \pi_{t+1}\left(\theta_{t+1}\right) \mu_{t+2}\left(\theta_{t+1}\right) F_{t}\left(\theta_{t+1}\right)
$$

For $t=T-1$, equation (29) holds with $\mu_{t+2}$ replaced by zero. Finally, in the limit case of time-separable preferences $\left(u_{h}=0\right)$, we have $E_{t}=F_{t}=0$.

Proposition 4 shows that savings wedges for habit formation preferences have three components. Consider the following hypothetical situation: the agent, after working in period $t$ and receiving the transfer $c_{t}\left(\theta^{t}\right)$, saves one unit of consumption for the following period. Then three effects change the agent's preferences over future states, and thereby the incentive to supply labor (or, put differently, the incentive to report truthfully) in the future.

First of all, there is the familiar wealth effect $D_{t}$. Saving one consumption unit at time $t$ yields a fixed number of extra consumption units in all states at time $t+1$. Since preferences are concave in consumption, the value of extra consumption is higher in states with low $c_{t+1}$. Low consumption states thus become relatively more attractive, and the agent's incentive to supply labor in period $t+1$ is reduced. This concavity/wealth effect is captured by the term

$$
D_{t}=d_{t}\left(\mathbb{E}\left[\tilde{U}_{t+1} \mid \theta^{t}, \underline{\theta}_{t+1}\right]-\mathbb{E}\left[\tilde{U}_{t+1} \mid \theta^{t}, \bar{\theta}_{t+1}\right]\right)
$$

\footnotetext{
${ }^{7}$ See Rogerson (1985) and Golosov, Kocherlakota, and Tsyvinski (2003), for instance.
} 
where $d_{t}=d_{t}\left(\theta^{t}\right)$ is a strictly positive number, and $\tilde{U}_{t+1}$ is the marginal utility of consumption in period $t+1$. Since the marginal utility of consumption is higher in low-consumption (low-skill) states, $D_{t}$ is positive and calls for a positive tax on savings. For time-separable preferences, Proposition 4 shows that $D_{t}$ is in fact the only component of the savings wedge.

The second component of the savings wedge is the immediate habit effect $E_{t}$. Saving in period $t$ reduces the agent's consumption and thereby diminishes the habit level at time $t+1$. Due to complementarity between habit and consumption, low-consumption states at time $t+1$ become relatively more attractive. This reduces the incentive to supply labor. Formally, the immediate habit effect can be expressed as

$$
E_{t}=e_{t}\left[u_{h}^{\prime}\left(\bar{c}_{t+1}, h_{t+1}\right)-u_{h}^{\prime}\left(\underline{c}_{t+1}, h_{t+1}\right)\right]
$$

where $e_{t}=e_{t}\left(\theta^{t}\right)$ is strictly positive, while $\bar{c}_{t+1}=c_{t+1}\left(\theta^{t}, \bar{\theta}_{t+1}\right), \underline{c}_{t+1}=c_{t+1}\left(\theta^{t}, \underline{\theta}_{t+1}\right)$ denotes consumption in period $t+1$. Since the cross derivative $u_{c h}^{\prime \prime}$ is positive by assumption, $E_{t}$ is positive. Hence the immediate habit effect goes in the same direction as the wealth effect and generates an additional motive for taxing savings.

Finally, the savings wedge has components $F_{t}$ that capture a subsequent habit effect. As the Lagrange multiplier $\mu_{t+2}$ in equation (29) suggests, these components relate to the incentive problem in period $t+2$, and can be written

$$
F_{t}=f_{t}\left[u_{h}^{\prime}\left(\bar{c}_{t+2}, h_{t+2}\right)-u_{h}^{\prime}\left(\underline{c}_{t+2}, h_{t+2}\right)\right]
$$

where $f_{t}=f_{t}\left(\theta^{t+1}\right)$ is strictly positive, and $\bar{c}_{t+2}=c_{t+2}\left(\theta^{t+1}, \bar{\theta}_{t+2}\right), \underline{c}_{t+2}=c_{t+2}\left(\theta^{t+1}, \underline{\theta}_{t+2}\right)$ represents consumption in period $t+2$. Complementarity between habit and consumption implies that $F_{t}$ is positive. Since the subsequent habit effect enters with a negative sign in equation (29), this effect calls for savings subsidies. The intuition is as follows. Saving at time $t$ increases consumption at $t+1$, and thereby the habit at $t+2$. Due to complementarity between habit and consumption, this helps with the incentive problem at $t+2$ by making high consumption relatively more attractive. Therefore saving at $t$ should be encouraged in order to relax the incentive problem in period $t+2$.

In summary, Propositions 3 and 4 identify forces that counteract the conventional distor- 
tions from time-separable Mirrlees models. While time-separable reasoning generates downward distortions on labor supply due to present self-selection problems, habit formation adds a motive to subsidize labor supply in order to facilitate self-selection in the future. Similarly, while time-separable reasoning generates savings distortions due to wealth effects, habit formation calls for savings subsidies as a means of changing the valuation of consumption in the future.

It should be noted that the implications of habit formation for savings wedges are somewhat less clear-cut than those for labor wedges, because immediate effects on preferences have to be traded off against subsequent effects. Yet, as long as incentive problems become more 'severe' over time, the forces pushing for savings subsidies will dominate. In finite-horizon models the incentive problem typically exacerbates over time indeed, because the planner can spread rewards over fewer and fewer periods as time progresses. This makes incentive provision more costly and causes the (conditional) consumption variance and the shadow cost of the incentive constraint to grow over time, other things being equal. As equations (29),(31),(32) show, both of these forces increase the subsequent habit effect relative to the immediate habit effect. We demonstrate the quantitative importance of this channel in Section 6.

\subsection{Generalizations of the basic model}

We made a number of simplifying assumptions that deserve a brief discussion. First of all, nonbinary skill types would make the model mathematically more tedious, but do not change the arguments underlying our results. The effect of habit formation on labor and savings wedges is precisely due to the fact that the incentive compatibility constraint (24) is relaxed if habits increase. With non-binary skill types, there is a multitude of (local) incentive compatibility constraints, and each constraint is of the same type as in the binary model. In particular, each constraint is relaxed if habits increase, and so there are the same habit effects on labor and savings wedges that we found above.

Our results also generalize to the case of persistent habits. Yet, the model quickly becomes intractable then. For instance, if habits follow the weighted average specification (3), increasing the persistence parameter $\eta$ from zero to a positive number entails that the habit at a given point in time affects the habits for the remainder of the agent's life. In that case, raising the habit relaxes the incentive compatibility constraints in all remaining periods, and the exposition 
of our results becomes more involved as we have to account for a large number of constraints and Lagrange multipliers. Apart from this complication, habit formation modifies labor and savings wedges in qualitatively the same way as above. In particular, the impact on savings wedges will still involve a trade-off between immediate and subsequent effects: habit $h_{t+1}$ is a function of $c_{t}$, while habit levels $h_{t+2}, h_{t+3}, \ldots, h_{T}$ react more strongly to $c_{t+1}$ than to $c_{t}$.

Finally, our results extend to the case of persistent skills (Markov skills). This case may seem somewhat less obvious than the previous two, since skill persistentence requires a novel recursive formulation: it becomes necessary to add promised utility for deviators as well as the past skill level to the vector of state variables. Moreover, there is an additional promise keeping constraint for agents who deviated in the past period. Yet, Propositions 3 and 4 hold true if the wedge components are suitably redefined. Further details can be found in Appendix B.

\section{Implications for the taxation of durable commodities}

Durable goods generate preference nonseparabilities that are closely related to habit formation, since the purchase of a durable affects the worker's valuation of future consumption plans. We exploit this analogy to show that our results on habit formation also provide insights on optimal commodity taxation in a framework with durable and nondurable goods.

Previous research has modeled durable goods as goods that are committed to before the resolution of uncertainty, while nondurable goods are decided only after the resolution of uncerainty. Assuming separability between pre-committed goods and post-uncertainty goods, the main result is that pre-committed goods should be subsidized relative to post-uncertainty goods (Cremer and Gahvari, 1995a,b). However, this approach abstracts from several key aspects of durability. First, nondurable consumption may take place both before and after the resolution of uncertainty. Moreover, even when nondurable consumption takes place after the resolution of uncertainty, it may need some pre-commitment - think of booking a holiday trip or buying tickets for the opera in advance. Second, durable and nondurable goods might be nonseparable. Examples include cars and the need for gasoline to do a trip, a refrigerator and beverages, a tax preparation software and the service of a tax accountant, and so on. The separability assumption imposed by previous research rules out such cases.

Following these arguments, we propose a model that distinguishes between durable and 
nondurable goods, and allows for nonseparabilities between those. For easy comparison with earlier findings, we derive our results in a two-period model with uncertainty in the second period only. We maintain the assumption that skills are binary. We consider two first-period goods: a nondurable good $c_{0}$, and a durable good $d_{0}$. Moreover, there is a (durable or nondurable) second-period good $c$. In the terminology of Cremer and Gahvari $(1995 \mathrm{a}, \mathrm{b})$, goods $c_{0}$ and $d_{0}$ are pre-committed, while $c$ is a post-uncertainty good. The agent evaluates consumption plans according to a utility function $u_{0}\left(c_{0}, d_{0}\right)+\beta u\left(c, d_{0}\right)$. As usual, the social planner minimizes the costs of providing a given level of ex-ante welfare. Without loss of generality, we choose units of measurement such that the technological rates of transformation between all goods equal one. The optimization problem then looks as follows:

$$
\begin{aligned}
& \min _{\left(c_{0}, d_{0}, c(\theta), y(\theta)\right)} \sum_{\theta \in\{\underline{\theta}, \bar{\theta}\}}\left[c_{0}+d_{0}+c(\theta)-y(\theta)\right] \pi(\theta) \\
& \text { s.t. } \\
& u\left(c(\bar{\theta}), d_{0}\right)-v(y(\bar{\theta}) / \bar{\theta}) \geq u\left(c(\underline{\theta}), d_{0}\right)-v(y(\underline{\theta}) / \bar{\theta}) \\
& \sum_{\theta \in\{\underline{\theta}, \bar{\theta}\}}\left[u_{0}\left(c_{0}, d_{0}\right)+\beta\left(u\left(c(\theta), d_{0}\right)-v(y(\theta) / \theta)\right)\right] \pi(\theta)=W
\end{aligned}
$$

Tax differentials between the durable good $d_{0}$ and the nondurable good $c_{0}$ are captured by the durability wedge

$$
\tau_{d}:=\frac{u_{0, d}^{\prime}\left(c_{0}, d_{0}\right)+\beta \mathbb{E}\left[u_{d}^{\prime}\left(c, d_{0}\right)\right]}{u_{0, c}^{\prime}\left(c_{0}, d_{0}\right)}-1
$$

Our main result of this section is as follows.

Proposition 5 (Durable commodities). Let $\left(c_{0}, d_{0}, c, y\right)$ be an optimal allocation, and let $\mu \geq$ 0 be the Lagrange multiplier associated with the incentive compatibility constraint (34). The durability wedge equals

$$
\tau_{d}=\mu\left[u_{d}^{\prime}\left(c(\underline{\theta}), d_{0}\right)-u_{d}^{\prime}\left(c(\bar{\theta}), d_{0}\right)\right] .
$$

In particular, $\tau_{d}$ is positive if $c$ and $d_{0}$ are substitutes $\left(u_{c d}^{\prime \prime} \leq 0\right)$, and negative if they are complements $\left(u_{c d}^{\prime \prime} \geq 0\right)$.

The key difference between durable and nondurable consumption is that durable consumption enters into the second-period incentive compatibility constraint. If durable consumption 
is complementary with the second-period good, it should be subsidized $\left(\tau_{d}<0\right)$ relative to nondurable consumption as Proposition 5 shows. The logic is very similar to the habit formation case. Durable consumption relaxes the incentive compatibility constraint in that case, because the difference between the utility of a truth-teller $u\left(c(\bar{\theta}), d_{0}\right)$ and the utility of a shirker $u\left(c(\underline{\theta}), d_{0}\right)$ increases in $d_{0}$ if $c$ and $d_{0}$ are complements. This effect is socially desirable because it facilitates the incentive problem, and thus durable consumption should be subsidized in that case. On the other hand, if durable consumption is substitutable with the second-period good, it should be taxed $\left(\tau_{d}>0\right)$ relative to nondurable consumption.

How durable goods affect the valuation of future consumption plans is ultimately an empirical question. Typically, durable goods have aspects of complementarity as well as substitutability with future goods (durables or nondurables). For instance, durable goods raise the value of repair/maintenance services. On the other hand, durable goods obviously reduce the need for future purchases of durables. Moreover, durable goods may replace some goods and services; for example, home production may become easier if the right tools and appliances are available. All in all, compared to the results by Cremer and Gahvari (1995a,b), the tax implications for durable goods become much more nuanced with the explicit model of durability we propose. In particular, it is no longer clear that housing (the prototype durable good) should receive a preferential tax treatment.

\section{A numerical example}

By means of a stylized example, this section addresses the quantitative importance of our theoretical findings on labor and savings taxation. The example captures some key features of the U.S. economy. In particular, the skill process matches the empirical life-cycle profile and the cross-sectional variance of wages. For computational reasons the example is deliberately simple in two aspects, however. First, the skill process is binary like in the theoretical model. Second, skill fluctuations are transitory. All our results are qualitatively robust to persistent shocks (as well as non-binary skills) as the theoretical analysis in Appendix B shows. However, the quantitative findings may depend on those assumptions. ${ }^{8}$

The recursive formulation from Section 3 gives rise to a straightforward computational

\footnotetext{
${ }^{8}$ The computational difficulties arising from persistent shocks are beyond the scope of this paper. See the concluding remarks for further discussion.
} 
approach. We first solve for the sequence of domain restrictions $\left(\operatorname{dom}_{t}(h)\right)_{h \in[c, \bar{c}], t=1, \ldots, T}$ following Lemma 2. We then exploit the Bellman equation (16) to obtain the sequence of cost functions $\left(C_{t}\right)_{t=1, \ldots, T}$ of the planner's problem using standard numerical optimization procedures. The associated policy functions are then iterated forward to generate the optimal allocation.

\subsection{Parameters}

There are $T=11$ periods with a duration of 5 years each. Agents enter the model at age 25, retire at age 65 , and die at age 80 . In each period before retirement, the skill $\theta_{t}$ is randomly drawn from a set $\left\{\underline{\theta}_{t}, \bar{\theta}_{t}\right\}$, where both realizations have equal probability and $\underline{\theta}_{t}<\bar{\theta}_{t}$. Draws are independent across agents and time. We choose the life-cycle profile of expected skills in line with Hansen (1993, Table II), who estimates relative efficiency profiles of workers in the United States over the years 1955 to 1988. Expected skills are hump-shaped over the life-cycle and peak in period 5 (age 45-49). The variance of log-skills is 0.351 and matches the cross-sectional variance of log-wages in the United States in the period 1967-2006 (Heathcote, Storesletten, and Violante, 2012, Table 3). Skills are deterministic after retirement and amount to one half of the average skill prior to retirement. We interpret this as skills for home production activities.

We set up habit formation in a Cobb-Douglas form: $u\left(c_{t}, h_{t}\right)=\tilde{u}\left(c_{t} h_{t}^{-\gamma}\right)$, where $\gamma$ is a number between zero and one that controls the importance of habits. ${ }^{9}$ In line with Diaz, PijoanMas, and Rios-Rull (2003), we choose $\gamma=0.75$. This value corresponds to the case of 'strong habits' explored by Carroll, Overland, and Weil (2000) and is reasonably close to empirical results by Fuhrer (2000), who estimates a value of 0.80 based on aggregate consumption data. In line with our theoretical model and estimations by Fuhrer (2000), habits are short-lived: $h_{t}=c_{t-1}$ for $t>1$. Period utility is of the CRRA type: $\tilde{u}(x)=x^{1-\sigma} /(1-\sigma)$, with $\sigma=3$. The discount factor is $\beta=0.98^{5}$ and the interest rate equals $R=1 / \beta$. The labor disutility function is $v(l)=\alpha l^{1+\frac{1}{\psi}} /\left(1+\frac{1}{\psi}\right)$, with a Frisch elasticity of labor supply of $\psi=0.5$, and $\alpha=1$.

We set the initial habit level to $h_{1}=0.7$. As we verify ex-post, this number coincides approximately with the agent's consumption level in the first period. We set the initial utility promise $W_{1}$ such that the planner's budget is balanced, i.e., $C_{1}\left(W_{1}, h_{1}\right)=0$. We verify that

\footnotetext{
${ }^{9}$ Another common specification of habit formation is the linear one: $u\left(c_{t}, h_{t}\right)=\tilde{u}\left(c_{t}-\gamma h_{t}\right)$. For our present purposes, the Cobb-Douglas formulation is more convenient, since period utilities are well defined whenever $c_{t}$ and $h_{t}$ are positive. The linear formulation has the drawback of ruling out all pairs $\left(c_{t}, h_{t}\right)$ with $c_{t}<\gamma h_{t}$, which makes the computation of the domain restriction and of the optimal allocation somewhat more cumbersome.
} 


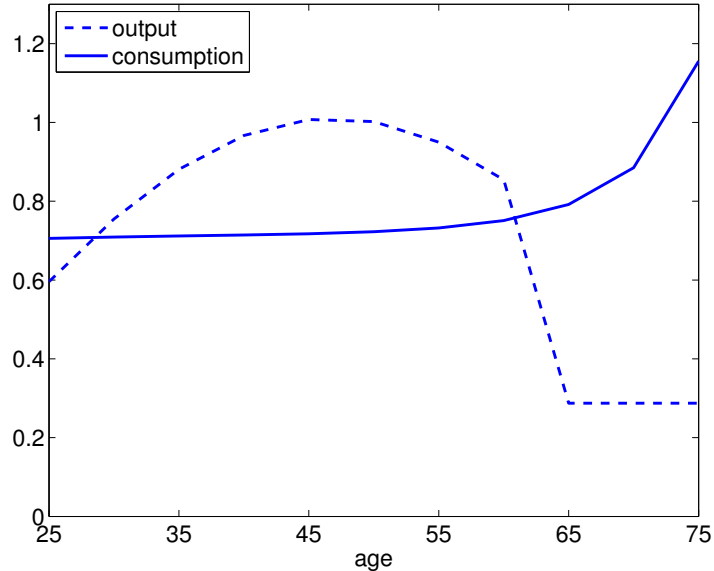

(a) Habit formation

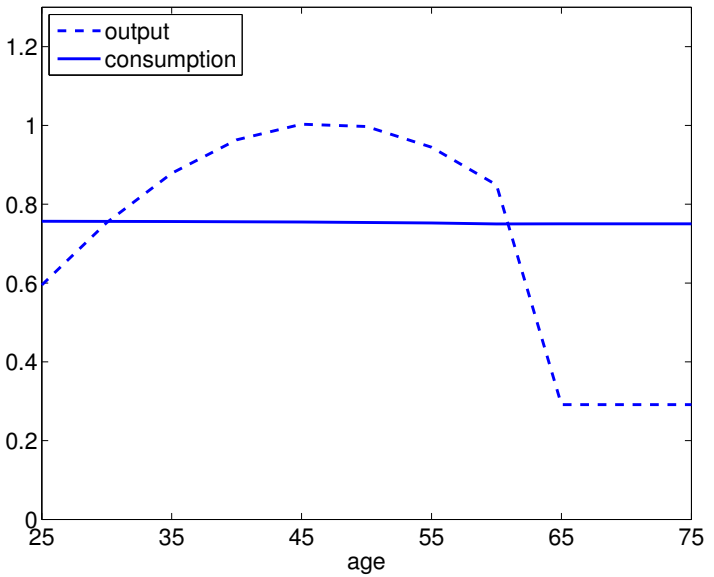

(b) Time-separable preferences

Figure 1: Expected consumption and output over the life-cycle

the bounds $\underline{c}, \bar{c}, \underline{y}$, and $\bar{y}$ are never binding for the optimal allocation starting from this initial state.

\subsection{Results}

Figure 1a presents the paths of expected output and consumption for the habit formation case $(\gamma=0.75)$. Expected output follows the hump-shaped pattern of the skill process, complemented by a moderate level of 'home production' output after retirement. Expected consumption increases over the life-cycle and grows by about 10 percent from age 25 to age 65 . Towards the end of the life-cycle, consumption growth accelerates as effects on future habits become less of a concern. ${ }^{10}$ Figure $1 \mathrm{~b}$ shows the corresponding paths for the case of time-separable preferences $(\gamma=0) .{ }^{11}$ The expected output path is very similar to the habit formation case. Expected consumption, however, is virtually flat (but slightly monotonically decreasing) for time-separable preferences. This shows that habit formation has a positive impact on the optimal growth rate of consumption.

Figure 2a displays expected labor wedges for the habit formation case. The habit effect

\footnotetext{
${ }^{10}$ We are aware that the consumption path during retirement is not well in line with empirical findings. A more sophisticated model of retirement would allow for stochastic mortality, and potentially for a structural change in the habit formation relation at the time of retirement. Stochastic mortality alone already mitigates consumption growth during retirement to a large extent, as effects of consumption on future preferences can never be fully ignored.

${ }^{11}$ To make the allocations comparable, we choose a scaling parameter of $\alpha=4.3$ for the time-separable case, such that the discounted value of life-time output (and consumption) coincides with the habit formation case. This adjustment has a negligible effect on labor and savings wedges: averaged over the life-cycle, labor wedges are 0.046 with $\alpha=1$ and 0.045 with $\alpha=4.3$, while average savings wedges amount to 0.011 in both cases.
} 

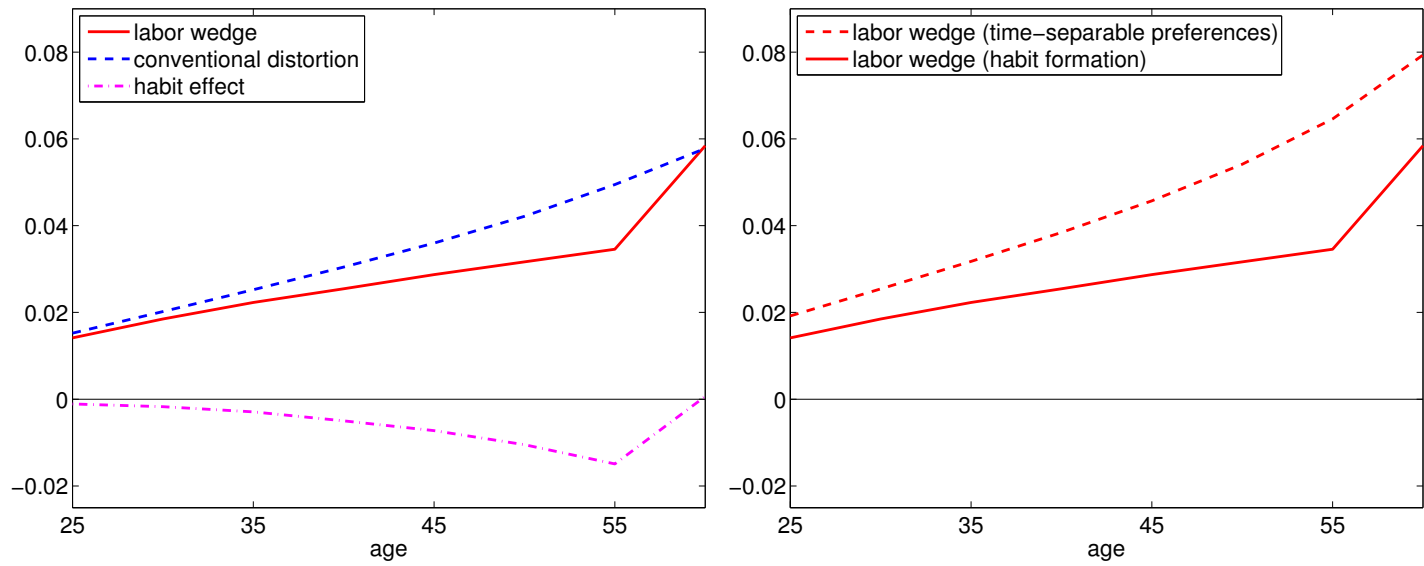

Figure 2: Expected labor wedges
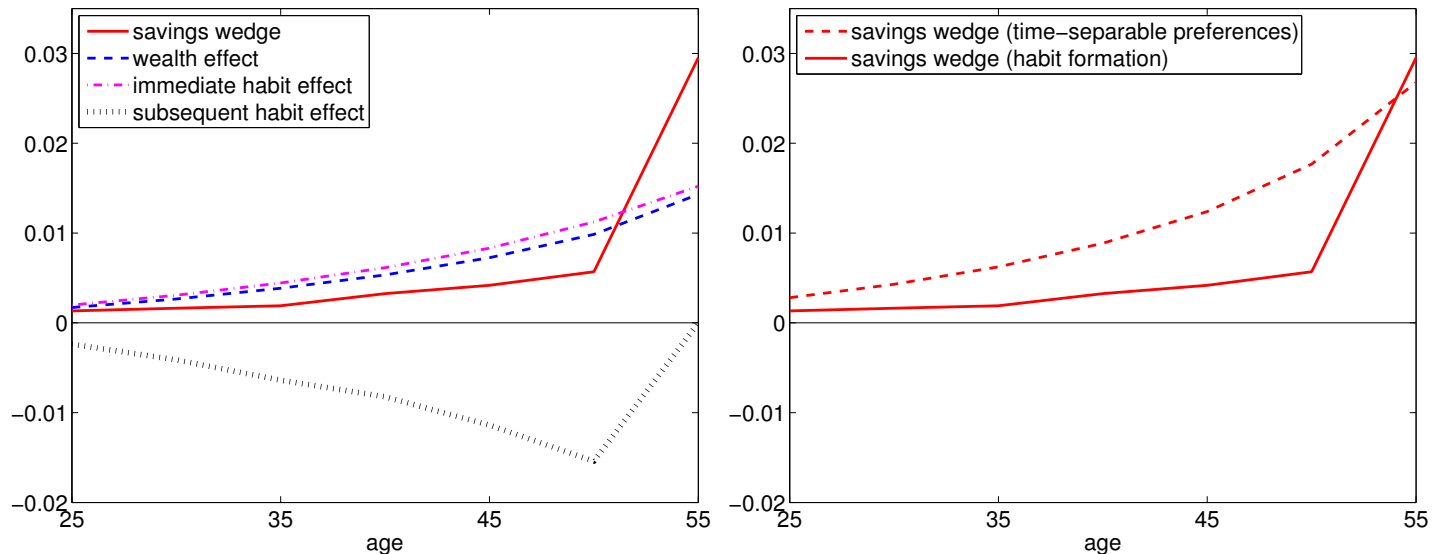

Figure 3: Expected savings wedges

$B_{t}$ calls for labor subsidies as outlined in our theoretical analysis. This effect is smaller in magnitude than the conventional Mirrleesian motive for labor taxation $A_{t}$. Thus, expected labor wedges are positive throughout the life-cycle, but significantly smaller than in the case of time-separable preferences (Figure 2b). Averaged over the life-cycle, labor wedges in the habit formation case drop by approximately 35 percent compared to the time-separable case.

Figure 3a decomposes expected savings wedges for the habit formation case into the wealth effect, immediate habit effect, and subsequent habit effect. Both habit effects are sizable, and in fact larger in magnitude than the conventional taxation motive caused by wealth effects. As argued in the theoretical section above, the subsequent habit effect calls for savings subsidies. This effect dominates the immediate habit effect (calling for savings taxes), and thus the total impact of habit formation on savings wedges is negative. The life-cycle average of the savings 
wedge with habit formation is 0.0068 (corresponding to a 7.1 percent tax on net interest). In the time-separable case it is 0.0113 (corresponding to a 11.6 percent tax on net interest); see Figure 3b. The difference becomes even more pronounced if we focus on workers aged between 25 and 50. For those workers, the average savings wedge with habit formation is only one third of the average savings wedge with time-separable preferences.

Recall that the subsequent habit effect encourages saving (and thus next period's consumption) in order to relax incentive problems in the subsequent future. The immediate habit effect, by contrast, discourages saving in order to relax the incentive problem in the immediately following period. Over time, incentive provision must rely less on future promises and more on costly consumption rewards. Therefore, relaxing incentive problems later in life seems relatively more important, which explains why the subsequent habit effect exceeds the immediate habit effect. The only exception to this rule appears at the end of the working life, when the subsequent habit effect by definition falls to zero.

\section{Concluding remarks}

Findings from macroeconomics, psychology and micro data provide evidence for habit formation in consumption preferences. This paper studies the effect of habit formation on optimal taxation in a model with private information. We characterize optimal allocations in terms of labor and savings wedges and identify several novel taxation motives.

Habit formation generates a motive to subsidize labor supply in order to encourage work (and indirectly consumption), as this makes agents 'hungrier' for consumption in the future and thereby relaxes future incentive problems. Hence, optimal labor wedges tend to be smaller in the presence of habit formation preferences. Habit formation also generates a motive for savings subsidies. If the worker consumes less in the present and more in the following period, due to habit formation the agent will be hungrier for consumption in subsequent periods. Thus, incentive problems in subsequent periods are relaxed if consumption in the present period becomes relatively more expensive, i.e., if savings are subsidized. Optimal savings wedges trade off this effect against the motive to tax savings to make the agent hungrier in the immediately following period (due to wealth and immediate habit effects).

Habit formation has effects on the valuation of future consumption plans that are very 
similar to that of durable consumption. We exploit this analogy to study the optimal taxation of durable and nondurable commodities. Finally, we demonstrate the quantitative importance of habit formation in a numerical example. Averaged over the life-cycle, optimal labor wedges drop by 35 percent, and optimal savings wedges by 40 percent, relative to the time-separable benchmark case.

Our numerical example captures some key aspects of the U.S. economy. For computational reasons, we assume that skill shocks are transitory. It is beyond the scope of this paper to deal with the computational challenges that arise when habit formation is combined with persistent shocks. The recursive formulation will then involve three continuous state variables (habits, promised utility, threat utility). The main difficulty, however, is that the domain of feasible utilities becomes a two-dimensional non-rectangular set that changes with time, the past shock and the habit level. To the best of our knowledge, the recursive contracting literature has not yet found approaches to deal with such problems.

Kapicka (2013) and Farhi and Werning (2013) compute models with time-separable preferences and persistent shocks that are continuous. Relying on the first-order approach and balanced-growth preferences, they are able to reduce the number of state variables to two. In principle, the first-order approach can also be applied in the habit formation case. Since the balanced-growth property breaks down, the number of state variables increases to four and the curse of dimensionality persists.

\section{Appendix}

\section{A Proofs}

Proof of Lemma 1. Since one-shot deviations are special cases of reporting strategies, incentive compatibility clearly implies that the temporary incentive constraint (10) holds for all $t$ and all $\theta^{t} \in \Theta^{t}, \hat{\theta} \in \Theta_{t}$.

For the reverse implication, we proceed by induction. Induction basis: Consider any function $\tilde{\sigma}_{1}: \Theta_{1} \rightarrow \Theta_{1}$. Define reporting strategy $\sigma^{(1)}$ by $\sigma_{1}^{(1)}\left(\theta_{1}\right)=\tilde{\sigma}_{1}\left(\theta_{1}\right)$ and $\sigma_{t}^{(1)}\left(\theta^{t}\right)=\theta_{t}$ for all 
$t>1$. Since the temporary incentive constraint (10) holds for $t=1$ we obtain the inequality

$$
\begin{aligned}
& w_{1}\left(\mathbf{c}, \mathbf{y} ; h_{1}\right) \\
= & \sum_{\theta_{1} \in \Theta_{1}}\left[u\left(c_{1}\left(\theta_{1}\right), h_{1}\right)-v\left(\frac{y_{1}\left(\theta_{1}\right)}{\theta_{1}}\right)+\beta w_{2}\left(c_{2}^{T}\left(\theta_{1}\right), y_{2}^{T}\left(\theta_{1}\right) ; H\left(c_{1}\left(\theta_{1}\right), h_{1}\right)\right)\right] \pi_{1}\left(\theta_{1}\right) \\
\geq \sum_{\theta_{1} \in \Theta_{1}}\left[u\left(c_{1}\left(\tilde{\sigma}_{1}\left(\theta_{1}\right)\right), h_{1}\right)-v\left(\frac{y_{1}\left(\tilde{\sigma}_{1}\left(\theta_{1}\right)\right)}{\theta_{1}}\right)\right] \pi_{1}\left(\theta_{1}\right) & \\
& +\beta \sum_{\theta_{1} \in \Theta_{1}} w_{2}\left(c_{2}^{T}\left(\tilde{\sigma}_{1}\left(\theta_{1}\right)\right), y_{2}^{T}\left(\tilde{\sigma}_{1}\left(\theta_{1}\right)\right) ; H\left(c_{1}\left(\tilde{\sigma}_{1}\left(\theta_{1}\right)\right), h_{1}\right)\right) \pi_{1}\left(\theta_{1}\right) \\
= & w_{1}\left(\mathbf{c} \circ \sigma^{(1)}, \mathbf{y} \circ \sigma^{(1)} ; h_{1}\right) .
\end{aligned}
$$

Hence, truth-telling dominates any strategy $\sigma^{(1)}$ involving deviations only in period 1.

Induction step: Suppose that $w_{1}\left(\mathbf{c}, \mathbf{y} ; h_{1}\right) \geq w_{1}\left(\mathbf{c} \circ \sigma^{(t-1)}, \mathbf{y} \circ \sigma^{(t-1)} ; h_{1}\right)$ holds for all strategies $\sigma^{(t-1)}$ involving deviations only in periods $1, \ldots, t-1$. Let $\sigma^{(t)}$ be any reporting strategy that involves deviations only in periods $1, \ldots, t$. Given a history $\theta^{t-1} \in \Theta^{t-1}$, let $\hat{\theta}^{t-1}=$ $\sigma^{(t)}\left(\theta^{t-1}\right)=\left(\sigma_{1}^{(t)}\left(\theta^{1}\right), \ldots, \sigma_{t-1}^{(t)}\left(\theta^{t-1}\right)\right)$ be the corresponding history of reports. Let $\sigma^{(t-1)}$ be the strategy that coincides with $\sigma^{(t)}$ in periods $1, \ldots, t-1$ and corresponds to truth-telling in periods $t, \ldots, T$. Since by assumption the temporary incentive constraint (10) holds for all histories $\left(\hat{\theta}^{t-1}, \theta_{t}\right), \theta_{t} \in \Theta_{t}$, we obtain

$$
\begin{aligned}
& w_{t}\left(\left(\mathbf{c} \circ \sigma^{(t-1)}\right)_{t}^{T}\left(\theta^{t-1}\right),\left(\mathbf{y} \circ \sigma^{(t-1)}\right)_{t}^{T}\left(\theta^{t-1}\right) ; h_{t}\left(\hat{\theta}^{t-1}\right)\right) \\
= & \sum_{\theta_{t}}\left[u\left(c_{t}\left(\hat{\theta}^{t-1}, \theta_{t}\right), h_{t}\left(\hat{\theta}^{t-1}\right)\right)-v\left(\frac{y_{t}\left(\hat{\theta}^{t-1}, \theta_{t}\right)}{\theta_{t}}\right)\right] \pi_{t}\left(\theta_{t}\right) \\
& +\beta \sum_{\theta_{t}} w_{t+1}\left(c_{t+1}^{T}\left(\hat{\theta}^{t-1}, \theta_{t}\right), y_{t+1}^{T}\left(\hat{\theta}^{t-1}, \theta_{t}\right) ; H\left(c_{t}\left(\hat{\theta}^{t-1}, \theta_{t}\right), h_{t}\left(\hat{\theta}^{t-1}\right)\right)\right) \pi_{t}\left(\theta_{t}\right) \\
\geq & \sum_{\theta_{t}}\left[u\left(c_{t}\left(\hat{\theta}^{t-1}, \sigma_{t}^{(t)}\left(\theta^{t}\right)\right), h_{t}\left(\hat{\theta}^{t-1}\right)\right)-v\left(\frac{y_{t}\left(\hat{\theta}^{t-1}, \sigma_{t}^{(t)}\left(\theta^{t}\right)\right)}{\theta_{t}}\right)\right] \pi_{t}\left(\theta_{t}\right) \\
& +\beta \sum_{\theta_{t}} w_{t+1}\left(c_{t+1}^{T}\left(\hat{\theta}^{t-1}, \sigma_{t}^{(t)}\left(\theta^{t}\right)\right), y_{t+1}^{T}\left(\hat{\theta}^{t-1}, \sigma_{t}^{(t)}\left(\theta^{t}\right)\right) ; H\left(c_{t}\left(\hat{\theta}^{t-1}, \sigma_{t}^{(t)}\left(\theta^{t}\right)\right), h_{t}\left(\hat{\theta}^{t-1}\right)\right)\right) \pi_{t}\left(\theta_{t}\right) \\
= & w_{t}\left(\left(\mathbf{c} \circ \sigma^{(t)}\right)_{t}^{T}\left(\theta^{t-1}\right),\left(\mathbf{y} \circ \sigma^{(t)}\right)_{t}^{T}\left(\theta^{t-1}\right) ; h_{t}\left(\hat{\theta}^{t-1}\right)\right) .
\end{aligned}
$$


This implies

$$
\begin{aligned}
& w_{1}\left(\mathbf{c} \circ \sigma^{(t-1)}, \mathbf{y} \circ \sigma^{(t-1)} ; h_{1}\right) \\
= & \sum_{s=1}^{t-1} \beta^{s-1} \sum_{\theta^{s} \in \Theta^{s}}\left[u\left(c_{s}\left(\sigma^{(t-1)}\left(\theta^{s}\right)\right), h_{s}\left(\sigma^{(t-1)}\left(\theta^{s-1}\right)\right)\right)-v\left(\frac{y_{s}\left(\sigma^{(t-1)}\left(\theta^{s}\right)\right)}{\theta_{s}}\right)\right] \Pi^{s}\left(\theta^{s}\right) \\
& +\beta^{t-1} \sum_{\theta^{t-1} \in \Theta^{t-1}} w_{t}\left(\left(\mathbf{c} \circ \sigma^{(t-1)}\right)_{t}^{T}\left(\theta^{t-1}\right),\left(\mathbf{y} \circ \sigma^{(t-1)}\right)_{t}^{T}\left(\theta^{t-1}\right) ; h_{t}\left(\hat{\theta}^{t-1}\right)\right) \Pi^{t-1}\left(\theta^{t-1}\right) \\
\geq & \sum_{s=1}^{t-1} \beta^{s-1} \sum_{\theta^{s} \in \Theta^{s}}\left[u\left(c_{s}\left(\sigma^{(t)}\left(\theta^{s}\right)\right), h_{s}\left(\sigma^{(t)}\left(\theta^{s-1}\right)\right)\right)-v\left(\frac{y_{s}\left(\sigma^{(t)}\left(\theta^{s}\right)\right)}{\theta_{s}}\right)\right] \Pi^{s}\left(\theta^{s}\right) \\
& +\beta^{t-1} \sum_{\theta^{t-1} \in \Theta^{t-1}} w_{t}\left(\left(\mathbf{c} \circ \sigma^{(t)}\right)_{t}^{T}\left(\theta^{t-1}\right),\left(\mathbf{y} \circ \sigma^{(t)}\right)_{t}^{T}\left(\theta^{t-1}\right) ; h_{t}\left(\hat{\theta}^{t-1}\right)\right) \Pi^{t-1}\left(\theta^{t-1}\right) \\
= & w_{1}\left(\mathbf{c} \circ \sigma^{(t)}, \mathbf{y} \circ \sigma^{(t)} ; h_{1}\right)
\end{aligned}
$$

and hence, using the induction hypothesis, we have $w_{1}\left(\mathbf{c}, \mathbf{y} ; h_{1}\right) \geq w_{1}\left(\mathbf{c} \circ \sigma^{(t)}, \mathbf{y} \circ \sigma^{(t)} ; h_{1}\right)$. Since $\sigma^{(t)}$ was an arbitrary strategy involving deviations only in periods $1, \ldots, t$, the induction step is complete. This completes the proof.

Proof of Lemma 2. Let $\tilde{U}\left(c^{*}, y^{*}\right)$ be the time- $t$ continuation utility of an agent with habit level $h_{t}=h$ who consumes a fixed level $c^{*}$ and produces a fixed output $y^{*}$ in periods $t, \ldots, T$ irrespective of his skill. Clearly all such allocations are incentive compatible. Setting $\bar{h}_{t}=h$, and $\bar{h}_{s}=H\left(\bar{c}, \bar{h}_{s-1}\right)$ for $s>t$, we have

$$
\tilde{U}(\bar{c}, \underline{y})=\sum_{s=t}^{T} \beta^{s-1}\left(u\left(\bar{c}, \bar{h}_{s}\right)-\sum_{\theta \in \Theta_{s}} \pi_{s}(\theta) v(\underline{y} / \theta)\right)
$$

and it is obvious that no other incentive compatible allocation can deliver a higher continuation utility. Similarly, setting $\underline{h}_{t}=h$, and $\underline{h}_{s}=H\left(\underline{c}, \underline{h}_{s-1}\right)$ for $s>t$, we have

$$
\tilde{U}(\underline{c}, \bar{y})=\sum_{s=t}^{T} \beta^{s-1}\left(u\left(\underline{c}, \underline{h}_{s}\right)-\sum_{\theta \in \Theta_{s}} \pi_{s}(\theta) v(\bar{y} / \theta)\right)
$$

and no other incentive compatible allocation can deliver a lower continuation utility.

To verify that $\operatorname{dom}_{t}(h)$ is an interval, note that $\operatorname{dom}_{t}(h)$ contains all numbers that can be written as $\tilde{U}\left(c^{*}, y^{*}\right)$ for some $c^{*} \in[\underline{c}, \bar{c}], y^{*} \in[\underline{y}, \bar{y}]$. By the continuity of $\tilde{U}$ (ensured by the continuity of $u, v, H)$ this covers all numbers in the interval $[\tilde{U}(\underline{c}, \bar{y}), \tilde{U}(\bar{c}, \underline{y})]$. Hence, 
$\operatorname{dom}_{t}(h) \supseteq[\tilde{U}(\underline{c}, \bar{y}), \tilde{U}(\bar{c}, \underline{y})]$. On the other hand, $\operatorname{dom}_{t}(h) \subseteq\left[\min \left(\operatorname{dom}_{t}(h)\right), \max \left(\operatorname{dom}_{t}(h)\right)\right]$. Using the results $\min \left(\operatorname{dom}_{t}(h)\right)=\tilde{U}(\underline{c}, \bar{y})$ and $\max \left(\operatorname{dom}_{t}(h)\right)=\tilde{U}(\bar{c}, \underline{y})$ from the first step, the two set inequalities taken together imply $\operatorname{dom}_{t}(h)=[\tilde{U}(\underline{c}, \bar{y}), \tilde{U}(\bar{c}, \underline{y})]$.

Proof of Proposition 2. Since the incentive compatibility constraint (24) is slack in all periods $t \geq t_{0}$, we have $\mu_{t}=0$ for $t \geq t_{0}$. Now the result follows from Propositions 3 and 4 .

Proof of Proposition 3. The (finite horizon) Bellman equation of the social planner problem is:

$$
\begin{aligned}
C_{t}\left(W_{t}, h_{t}\right)= & \min _{c_{t}^{i}, y_{t}^{i}, W_{t+1}^{i}} \sum_{i=H, L}\left[c_{t}^{i}-y_{t}^{i}+q C_{t+1}\left(W_{t+1}^{i}, c_{t}^{i}\right)\right] \pi_{t}\left(\theta_{t}^{i}\right) \\
\text { s.t. } & \\
& u\left(c_{t}^{H}, h_{t}\right)-v\left(y_{t}^{H} / \theta_{t}^{H}\right)+\beta W_{t+1}^{H} \geq u\left(c_{t}^{L}, h_{t}\right)-v\left(y_{t}^{L} / \theta_{t}^{H}\right)+\beta W_{t+1}^{L} \\
& \sum_{i=H, L}\left[u\left(c_{t}^{i}, h_{t}\right)-v\left(y_{t}^{i} / \theta_{t}^{i}\right)+\beta W_{t+1}^{i}\right] \pi_{t}\left(\theta_{t}^{i}\right)=W_{t}
\end{aligned}
$$

Problem (38) has the following first-order conditions for consumption

$$
\begin{aligned}
& 0=\pi_{t}\left(\theta_{t}^{H}\right)\left[1+q C_{t+1, h}\left(W_{t+1}^{H}, c_{t}^{H}\right)\right]-\lambda_{t} u_{c}\left(c_{t}^{H}, h_{t}\right) \pi_{t}\left(\theta_{t}^{H}\right)-\mu_{t} u_{c}\left(c_{t}^{H}, h_{t}\right) \\
& 0=\pi_{t}\left(\theta_{t}^{L}\right)\left[1+q C_{t+1, h}\left(W_{t+1}^{L}, c_{t}^{L}\right)\right]-\lambda_{t} u_{c}\left(c_{t}^{L}, h_{t}\right) \pi_{t}\left(\theta_{t}^{L}\right)+\mu_{t} u_{c}\left(c_{t}^{L}, h_{t}\right)
\end{aligned}
$$

for output

$$
\begin{aligned}
0 & =-\pi_{t}\left(\theta_{t}^{H}\right)+\lambda_{t} \frac{v^{\prime}\left(y_{t}^{H} / \theta_{t}^{H}\right)}{\theta_{t}^{H}} \pi_{t}\left(\theta_{t}^{H}\right)+\mu_{t} \frac{v^{\prime}\left(y_{t}^{H} / \theta_{t}^{H}\right)}{\theta_{t}^{H}} \\
0 & =-\pi_{t}\left(\theta_{t}^{L}\right)+\lambda_{t} \frac{v^{\prime}\left(y_{t}^{L} / \theta_{t}^{L}\right)}{\theta_{t}^{L}} \pi_{t}\left(\theta_{t}^{L}\right)-\mu_{t} \frac{v^{\prime}\left(y_{t}^{L} / \theta_{t}^{H}\right)}{\theta_{t}^{H}}
\end{aligned}
$$

and for continuation utilities

$$
\begin{aligned}
0 & =\pi_{t}\left(\theta_{t}^{H}\right) q C_{t+1, W}\left(W_{t+1}^{H}, c_{t}^{H}\right)-\lambda_{t} \beta \pi_{t}\left(\theta_{t}^{H}\right)-\mu_{t} \beta \\
0 & =\pi_{t}\left(\theta_{t}^{L}\right) q C_{t+1, W}\left(W_{t+1}^{L}, c_{t}^{L}\right)-\lambda_{t} \beta \pi_{t}\left(\theta_{t}^{L}\right)+\mu_{t} \beta .
\end{aligned}
$$

We begin with the labor wedge of the high-skilled worker. Combine the first-order condition 
for $y_{t}^{H}$ with that for $c_{t}^{H}$ to obtain

$$
\frac{1+q C_{t+1, h}\left(W_{t+1}^{H}, c_{t}^{H}\right)}{u_{c}\left(c_{t}^{H}, h_{t}\right)}=\frac{\theta_{t}^{H}}{v^{\prime}\left(y_{t}^{H} / \theta_{t}^{H}\right)}
$$

By the envelope theorem, applied to the Bellman equation (38) at date $t+1$, we have

$$
\begin{aligned}
C_{t+1, W}\left(W_{t+1}^{H}, c_{t}^{H}\right) & =\lambda_{t+1}^{H} \\
C_{t+1, h}\left(W_{t+1}^{H}, c_{t}^{H}\right) & =-\lambda_{t+1}^{H} \sum_{j} u_{h}\left(c_{t+1}^{H j}, c_{t}^{H}\right) \pi_{t+1}\left(\theta_{t+1}^{j}\right)-\mu_{t+1}^{H}\left[u_{h}\left(c_{t+1}^{H H}, c_{t}^{H}\right)-u_{h}\left(c_{t+1}^{H L}, c_{t}^{H}(\Varangle \oint)\right.\right.
\end{aligned}
$$

Hence we can rewrite (47) as

$$
\begin{aligned}
\frac{\theta_{t}^{H}}{v^{\prime}\left(y_{t}^{H} / \theta_{t}^{H}\right)} u_{c}\left(c_{t}^{H}, h_{t}\right)= & 1-q C_{t+1, W}\left(W_{t+1}^{H}, c_{t}^{H}\right) \sum_{j} u_{h}\left(c_{t+1}^{H j}, c_{t}^{H}\right) \pi_{t+1}\left(\theta_{t+1}^{j}\right) \\
& -q \mu_{t+1}^{H}\left[u_{h}\left(c_{t+1}^{H H}, c_{t}^{H}\right)-u_{h}\left(c_{t+1}^{H L}, c_{t}^{H}\right)\right] .
\end{aligned}
$$

Combine the first-order condition for $W_{t+1}^{H}$ with the first-order condition for $y_{t}^{H}$ to obtain

$$
q C_{t+1, W}\left(W_{t+1}^{H}, c_{t}^{i}\right)=\beta \frac{\theta_{t}^{H}}{v^{\prime}\left(y_{t}^{H} / \theta_{t}^{H}\right)} .
$$

Use this to rewrite (50) as follows:

$$
\mathbb{E}\left[\tilde{U}_{t} \mid \theta^{t-1}, \theta_{t}^{H}\right]=\frac{v^{\prime}\left(y_{t}^{H} / \theta_{t}^{H}\right)}{\theta_{t}^{H}}\left(1-q \mu_{t+1}^{H}\left[u_{h}\left(c_{t+1}^{H H}, c_{t}^{H}\right)-u_{h}\left(c_{t+1}^{H L}, c_{t}^{H}\right)\right]\right)
$$

Therefore the labor wedge is

$$
\tau_{y, t}^{H}=-\mu_{t+1}^{H} \frac{q v^{\prime}\left(y_{t}^{H} / \theta_{t}^{H}\right)}{\theta_{t}^{H} \mathbb{E}\left[\tilde{U}_{t} \mid \theta^{t-1}, \theta_{t}^{H}\right]}\left[u_{h}\left(c_{t+1}^{H H}, c_{t}^{H}\right)-u_{h}\left(c_{t+1}^{H L}, c_{t}^{H}\right)\right]
$$

Using the first-order condition for $y_{t}^{H}$ and the identity $q \pi_{t}\left(\theta_{t}^{H}\right) \lambda_{t+1}^{H}=\beta\left(\lambda_{t} \pi_{t}\left(\theta_{t}^{H}\right)+\mu_{t}\right)$, and defining

$$
B_{t}^{H}=\frac{\beta\left[u_{h}\left(c_{t+1}^{H H}, c_{t}^{H}\right)-u_{h}\left(c_{t+1}^{H L}, c_{t}^{H}\right)\right]}{\lambda_{t+1}^{H} \mathbb{E}\left[\tilde{U}_{t} \mid \theta^{t-1}, \theta_{t}^{H}\right]},
$$

the labor wedge is $\tau_{y, t}^{H}=-\mu_{t+1}^{H} B_{t}^{H}$.

We now turn to the labor wedge of the low-skilled worker. First we write the first-order 
condition for $c_{t}^{L}$ as

$$
\left[\lambda_{t} \pi_{t}\left(\theta_{t}^{L}\right)-\mu_{t}\right] u_{c}\left(c_{t}^{L}, h_{t}\right)-\pi_{t}\left(\theta_{t}^{L}\right)=q \pi_{t}\left(\theta_{t}^{L}\right) C_{t+1, h}\left(W_{t+1}^{L}, c_{t}^{L}\right)
$$

The envelope theorem, applied to the Bellman equation (38) at date $t+1$, yields

$$
\begin{aligned}
C_{t+1, W}\left(W_{t+1}^{L}, c_{t}^{L}\right) & =\lambda_{t+1}^{L} \\
C_{t+1, h}\left(W_{t+1}^{L}, c_{t}^{L}\right) & \left.=-\lambda_{t+1}^{L} \sum_{j} u_{h}\left(c_{t+1}^{L j}, c_{t}^{L}\right) \pi_{t+1}\left(\theta_{t+1}^{j}\right)-\mu_{t+1}^{L}\left[u_{h}\left(c_{t+1}^{L H}, c_{t}^{L}\right)-u_{h}\left(c_{t+1}^{L L}, c_{t}^{L}\right)^{\dagger}\right]\right)
\end{aligned}
$$

Combined with the first-order condition for $W_{t+1}^{L}$, we obtain

$$
\begin{aligned}
q \pi_{t}\left(\theta_{t}^{L}\right) C_{t+1, h}\left(W_{t+1}^{L}, c_{t}^{L}\right)= & -\lambda_{t} \pi_{t}\left(\theta_{t}^{L}\right) \beta \sum_{j} u_{h}\left(c_{t+1}^{L j}, c_{t}^{L}\right) \pi_{t+1}\left(\theta_{t+1}^{j}\right)+\mu_{t} \beta \sum_{j} u_{h}\left(c_{t+1}^{L j}, c_{t}^{L}\right) \pi_{t+1}\left(\theta_{t+58}^{j}()\right) \\
& -\mu_{t+1}^{L} \pi_{t}\left(\theta_{t}^{L}\right) q\left[u_{h}\left(c_{t+1}^{L H}, c_{t}^{L}\right)-u_{h}\left(c_{t+1}^{L L}, c_{t}^{L}\right)\right] .
\end{aligned}
$$

We substitute this in the first-order condition for $c_{t}^{L}$ to obtain

$$
\begin{aligned}
& \lambda_{t} \pi_{t}\left(\theta_{t}^{L}\right) \mathbb{E}\left[\tilde{U}_{t} \mid \theta^{t-1}, \theta_{t}^{L}\right]-\pi_{t}\left(\theta_{t}^{L}\right) \\
= & \mu_{t} \mathbb{E}\left[\tilde{U}_{t} \mid \theta^{t-1}, \theta_{t}^{L}\right]-\mu_{t+1}^{L} \pi_{t}\left(\theta_{t}^{L}\right) q\left[u_{h}\left(c_{t+1}^{L H}, c_{t}^{L}\right)-u_{h}\left(c_{t+1}^{L L}, c_{t}^{L}\right)\right] .
\end{aligned}
$$

Now we use the first-order condition for $y_{t}^{L}$ to replace $\pi_{t}\left(\theta_{t}^{L}\right)$ :

$$
\begin{aligned}
& \lambda_{t} \pi_{t}\left(\theta_{t}^{L}\right)\left\{\mathbb{E}\left[\tilde{U}_{t} \mid \theta^{t-1}, \theta_{t}^{L}\right]-\frac{v^{\prime}\left(y_{t}^{L} / \theta_{t}^{L}\right)}{\theta_{t}^{L}}\right\} \\
= & \mu_{t}\left\{\mathbb{E}\left[\tilde{U}_{t} \mid \theta^{t-1}, \theta_{t}^{L}\right]-\frac{v^{\prime}\left(y_{t}^{L} / \theta_{t}^{H}\right)}{\theta_{t}^{H}}\right\}-\mu_{t+1}^{L} \pi_{t}\left(\theta_{t}^{L}\right) q\left[u_{h}\left(c_{t+1}^{L H}, c_{t}^{L}\right)-u_{h}\left(c_{t+1}^{L L}, c_{t}^{L}\right)\right]
\end{aligned}
$$

This can be rewritten as

$$
\begin{aligned}
& \left(\lambda_{t} \pi_{t}\left(\theta_{t}^{L}\right)-\mu_{t}\right)\left\{\mathbb{E}\left[\tilde{U}_{t} \mid \theta^{t-1}, \theta_{t}^{L}\right]-\frac{v^{\prime}\left(y_{t}^{L} / \theta_{t}^{L}\right)}{\theta_{t}^{L}}\right\} \\
= & \mu_{t}\left\{\frac{v^{\prime}\left(y_{t}^{L} / \theta_{t}^{L}\right)}{\theta_{t}^{L}}-\frac{v^{\prime}\left(y_{t}^{L} / \theta_{t}^{H}\right)}{\theta_{t}^{H}}\right\}-\mu_{t+1}^{L} \pi_{t}\left(\theta_{t}^{L}\right) q\left[u_{h}\left(c_{t+1}^{L H}, c_{t}^{L}\right)-u_{h}\left(c_{t+1}^{L L}, c_{t}^{L}\right)\right] .
\end{aligned}
$$


Using the identity $\pi_{t}\left(\theta_{t}^{L}\right) q \lambda_{t+1}^{L}=\beta\left(\lambda_{t} \pi_{t}\left(\theta_{t}^{L}\right)-\mu_{t}\right)$ and defining

$$
\begin{aligned}
A_{t}^{L} & =\frac{\beta}{q \pi_{t}\left(\theta_{t}^{L}\right) \lambda_{t+1}^{L} \mathbb{E}\left[\tilde{U}_{t} \mid \theta^{t-1}, \theta_{t}^{L}\right]}\left[\frac{v^{\prime}\left(y_{t}^{L} / \theta_{t}^{L}\right)}{\theta_{t}^{L}}-\frac{v^{\prime}\left(y_{t}^{L} / \theta_{t}^{H}\right)}{\theta_{t}^{H}}\right] \\
B_{t}^{L} & =\frac{\beta\left[u_{h}\left(c_{t+1}^{L H}, c_{t}^{L}\right)-u_{h}\left(c_{t+1}^{L L}, c_{t}^{L}\right)\right]}{\lambda_{t+1}^{L} \mathbb{E}\left[\tilde{U}_{t} \mid \theta^{t-1}, \theta_{t}^{L}\right]}
\end{aligned}
$$

the labor wedge is hence $\tau_{y, t}^{L}=\mu_{t} A_{t}^{L}-\mu_{t+1}^{L} B_{t}^{L}$. This completes the proof.

Proof of Proposition 4. We begin with the savings wedge for the high-skilled worker. Combine the first-order condition for consumption (41) and the envelope condition (49) to obtain

$$
\begin{aligned}
& \frac{\lambda_{t} \pi_{t}\left(\theta_{t}^{H}\right)+\mu_{t}}{\pi_{t}\left(\theta_{t}^{H}\right)} u_{c}\left(c_{t}^{H}, h_{t}\right)-1 \\
= & -q \lambda_{t+1}^{H} \sum_{j} u_{h}\left(c_{t+1}^{H j}, c_{t}^{H}\right) \pi_{t+1}\left(\theta_{t+1}^{j}\right)-q \mu_{t+1}^{H}\left[u_{h}\left(c_{t+1}^{H H}, c_{t}^{H}\right)-u_{h}\left(c_{t+1}^{H L}, c_{t}^{H}\right)\right] .
\end{aligned}
$$

Using the identity $q \pi_{t}\left(\theta_{t}^{H}\right) \lambda_{t+1}^{H}=\beta\left(\lambda_{t} \pi_{t}\left(\theta_{t}^{H}\right)+\mu_{t}\right)$, we can rewrite the previous equation as

$$
\frac{q \lambda_{t+1}^{H}}{\beta} \mathbb{E}\left[\tilde{U}_{t} \mid \theta^{t-1}, \theta_{t}^{H}\right]=1-q \mu_{t+1}^{H}\left[u_{h}\left(c_{t+1}^{H H}, c_{t}^{H}\right)-u_{h}\left(c_{t+1}^{H L}, c_{t}^{H}\right)\right]
$$

The first-order conditions for consumption in period $t+1$ are

$$
\begin{aligned}
& 0=\pi_{t+1}\left(\theta_{t+1}^{H}\right)\left[1+q C_{t+2, h}\left(W_{t+2}^{H H}, c_{t+1}^{H H}\right)\right]-\lambda_{t+1}^{H} u_{c}\left(c_{t+1}^{H H}, c_{t}^{H}\right) \pi_{t+1}\left(\theta_{t+1}^{H}\right)-\mu_{t+1}^{H} u_{c}\left(c_{t+1}^{H H},\left(\epsilon_{t}^{\sharp 0}\right)\right) \\
& \left.0=\pi_{t+1}\left(\theta_{t+1}^{L}\right)\left[1+q C_{t+2, h}\left(W_{t+2}^{H L}, c_{t+1}^{H L}\right)\right]-\lambda_{t+1}^{H} u_{c}\left(c_{t+1}^{H L}, c_{t}^{H}\right) \pi_{t+1}\left(\theta_{t+1}^{L}\right)+\mu_{t+1}^{H} u_{c}\left(c_{t+1}^{H L}, c_{t}^{H} t\right) 1 .\right)
\end{aligned}
$$

Summing up these conditions and substituting the result into the previous equation yields

$$
\begin{aligned}
\frac{q \lambda_{t+1}^{H}}{\beta} \mathbb{E}\left[\tilde{U}_{t} \mid \theta^{t-1}, \theta_{t}^{H}\right]= & -\pi_{t+1}\left(\theta_{t+1}^{L}\right) q C_{t+2, h}\left(W_{t+2}^{H L}, c_{t+1}^{H L}\right)-\pi_{t+1}\left(\theta_{t+1}^{H}\right) q C_{t+2, h}\left(W_{t+2}^{H H}, c_{t+1}^{H H}\right) \\
& +\lambda_{t+1}^{H}\left[u_{c}\left(c_{t+1}^{H H}, c_{t}^{H}\right) \pi_{t+1}\left(\theta_{t+1}^{H}\right)+u_{c}\left(c_{t+1}^{H L}, c_{t}^{H}\right) \pi_{t+1}\left(\theta_{t+1}^{L}\right)\right] \\
& -\mu_{t+1}^{H}\left[u_{c}\left(c_{t+1}^{H L}, c_{t}^{H}\right)-u_{c}\left(c_{t+1}^{H H}, c_{t}^{H}\right)\right]-q \mu_{t+1}^{H}\left[u_{h}\left(c_{t+1}^{H H}, c_{t}^{H}\right)-u_{h}\left(c_{t+1}^{H L}, c_{t}^{H}(\mathrm{~J})\right)\right.
\end{aligned}
$$


We use the envelope conditions for period $t+2$ to replace $C_{t+2, h}$. This gives, after some algebra,

$$
\begin{aligned}
q \lambda_{t+1}^{H} \mathbb{E}\left[\tilde{U}_{t} \mid \theta^{t-1}, \theta_{t}^{H}\right]= & \beta \lambda_{t+1}^{H} \mathbb{E}\left[\tilde{U}_{t+1} \mid \theta^{t-1}, \theta_{t}^{H}\right] \\
& -\mu_{t+1}^{H} \beta\left(\mathbb{E}\left[\tilde{U}_{t+1} \mid \theta^{t-1}, \theta_{t}^{H}, \theta_{t+1}^{L}\right]-\mathbb{E}\left[\tilde{U}_{t+1} \mid \theta^{t-1}, \theta_{t}^{H}, \theta_{t+1}^{H}\right]\right) \\
& -q \mu_{t+1}^{H} \beta\left[u_{h}\left(c_{t+1}^{H H}, c_{t}^{H}\right)-u_{h}\left(c_{t+1}^{H L}, c_{t}^{H}\right)\right] \\
& +q \pi_{t+1}\left(\theta_{t+1}^{H}\right) \mu_{t+2}^{H H} \beta\left[u_{h}\left(c_{t+2}^{H H}, c_{t+1}^{H H}\right)-u_{h}\left(c_{t+2}^{H H}, c_{t+1}^{H H}\right)\right] \\
& +q \pi_{t+1}\left(\theta_{t+1}^{L}\right) \mu_{t+2}^{H L} \beta\left[u_{h}\left(c_{t+2}^{H L H}, c_{t+1}^{H L}\right)-u_{h}\left(c_{t+2}^{H L L}, c_{t+1}^{H L}\right)\right] .
\end{aligned}
$$

Setting $i=H$ and defining

$$
\begin{aligned}
D_{t}^{i} & =\frac{\mathbb{E}\left[\tilde{U}_{t+1} \mid \theta^{t-1}, \theta_{t}^{i}, \theta_{t+1}^{L}\right]-\mathbb{E}\left[\tilde{U}_{t+1} \mid \theta^{t-1}, \theta_{t}^{i}, \theta_{t+1}^{H}\right]}{\lambda_{t+1}^{i} \mathbb{E}\left[\tilde{U}_{t+1} \mid \theta^{t-1}, \theta_{t}^{i}\right]} \\
E_{t}^{i} & =\frac{q\left[u_{h}\left(c_{t+1}^{i H}, c_{t}^{i}\right)-u_{h}\left(c_{t+1}^{i L}, c_{t}^{i}\right)\right]}{\lambda_{t+1}^{i} \mathbb{E}\left[\tilde{U}_{t+1} \mid \theta^{t-1}, \theta_{t}^{i}\right]} \\
F_{t}^{i j} & =\frac{q\left[u_{h}\left(c_{t+2}^{i j H}, c_{t+1}^{i j}\right)-u_{h}\left(c_{t+2}^{i j L}, c_{t+1}^{i j}\right)\right]}{\lambda_{t+1}^{i} \mathbb{E}\left[\tilde{U}_{t+1} \mid \theta^{t-1}, \theta_{t}^{i}\right]}, \quad j=L, H,
\end{aligned}
$$

the savings wedge is hence

$$
\tau_{s, t}^{i}=\mu_{t+1}^{i} D_{t}^{i}+\mu_{t+1}^{i} E_{t}^{i}+\pi_{t+1}\left(\theta_{t+1}^{H}\right) \mu_{t+2}^{i H} F_{t}^{i H}+\pi_{t+1}\left(\theta_{t+1}^{L}\right) \mu_{t+2}^{i L} F_{t}^{i L} .
$$

Regarding the savings wedge of the low-skilled worker, we can follow the same steps to show that formula (83) applies if we set $i=L$ in definitions (80), (81), (82). This completes the proof.

Proof of Proposition 5. The result follows immediately from the first-order conditions

$$
\begin{aligned}
0 & =1-\lambda u_{0, c}^{\prime}\left(c_{0}, d_{0}\right) \\
0 & =1-\lambda\left[u_{0, d}^{\prime}\left(c_{0}, d_{0}\right)+\beta \mathbb{E}\left[u_{d}^{\prime}\left(c, d_{0}\right)\right]\right]+\mu\left[u_{d}^{\prime}\left(c(\underline{\theta}), d_{0}\right)-u_{d}^{\prime}\left(c(\bar{\theta}), d_{0}\right)\right] .
\end{aligned}
$$




\section{B Persistent skills}

We assume that skills form a Markov chain with transition probabilities $\pi_{t}\left(\theta_{t} \mid \theta_{t-1}\right)$, where $\pi_{t}\left(\theta_{t}^{H} \mid \theta_{t-1}^{H}\right)>\pi_{t}\left(\theta_{t}^{H} \mid \theta_{t-1}^{L}\right)$. Following the insights from Fernandes and Phelan (2000), the Markov property imposes two additional state variables (past skill type $\theta_{t-1}$, threat utility $\left.\hat{W}_{t}\right)$ and one additional constraint (threat keeping constraint). We maintain the assumption that only the downward incentive compatibility constraints bind. Hence, we abstract from the possibility that a low-skilled worker reports being high-skilled. Due to this assumption, a high skill report may only come from a high-skilled worker, and there is common knowledge of preferences in that case. A low skill report may come from both types of workers. Since those workers face different probability distributions over future uncertainty, we need to impose a threat keeping constraint in that case.

If the past skill is low, the recursive formulation of the social planning problem is therefore

$$
C_{t}\left(W_{t}, \hat{W}_{t}, h_{t}, \theta_{t-1}^{L}\right)=\min _{c_{t}^{i}, y_{t}^{i}, W_{t+1}^{i}, \hat{W}_{t+1}^{L}} \sum_{i=H, L}\left[c_{t}^{i}-y_{t}^{i}+q C_{t+1}\left(W_{t+1}^{i}, \hat{W}_{t+1}^{i}, c_{t}^{i}, \theta_{t}^{i}\right)\right] \pi_{t}\left(\theta_{t}^{i} \mid \theta_{t-1}^{L}\right)
$$

s.t.

$$
\begin{gathered}
W_{t}=\sum_{i=H, L}\left[u\left(c_{t}^{i}, h_{t}\right)-v\left(y_{t}^{i} / \theta_{t}^{i}\right)+\beta W_{t+1}^{i}\right] \pi_{t}\left(\theta_{t}^{i} \mid \theta_{t-1}^{L}\right) \\
\hat{W}_{t}=\sum_{i=H, L}\left[u\left(c_{t}^{i}, h_{t}\right)-v\left(y_{t}^{i} / \theta_{t}^{i}\right)+\beta W_{t+1}^{i}\right] \pi_{t}\left(\theta_{t}^{i} \mid \theta_{t-1}^{H}\right) \\
u\left(c_{t}^{H}, h_{t}\right)-v\left(y_{t}^{H} / \theta_{t}^{H}\right)+\beta W_{t+1}^{H} \geq u\left(c_{t}^{L}, h_{t}\right)-v\left(y_{t}^{L} / \theta_{t}^{H}\right)+\beta \hat{W}_{t+1}^{L} .
\end{gathered}
$$

If the past skill is high, the formulation is

$$
\begin{gathered}
C_{t}\left(W_{t}, h_{t}, \theta_{t-1}^{H}\right)=\min _{c_{t}^{i}, y_{t}^{i}, W_{t+1}^{i}, \hat{W}_{t+1}^{L}} \sum_{i=H, L}\left[c_{t}^{i}-y_{t}^{i}+q C_{t+1}\left(W_{t+1}^{i}, \hat{W}_{t+1}^{i}, c_{t}^{i}, \theta_{t}^{i}\right)\right] \pi_{t}\left(\theta_{t}^{i} \mid \theta_{t-1}^{H}\right) \\
\text { s.t. } \\
W_{t}=\sum_{i=H, L}\left[u\left(c_{t}^{i}, h_{t}\right)-v\left(y_{t}^{i} / \theta_{t}^{i}\right)+\beta W_{t+1}^{i}\right] \pi_{t}\left(\theta_{t}^{i} \mid \theta_{t-1}^{H}\right) \\
u\left(c_{t}^{H}, h_{t}\right)-v\left(y_{t}^{H} / \theta_{t}^{H}\right)+\beta W_{t+1}^{H} \geq u\left(c_{t}^{L}, h_{t}\right)-v\left(y_{t}^{L} / \theta_{t}^{H}\right)+\beta \hat{W}_{t+1}^{L} .
\end{gathered}
$$


Introduce symbol $\hat{\lambda}$ for the Lagrange multiplier of the threat keeping constraint (88), and define

$$
\begin{aligned}
B_{t}^{H} & =\frac{\beta\left[u_{h}\left(c_{t+1}^{H H}, c_{t}^{H}\right)-u_{h}\left(c_{t+1}^{H L}, c_{t}^{H}\right)\right]}{\lambda_{t+1}^{H} \mathbb{E}\left[\tilde{U}_{t} \mid \theta^{t-1}, \theta_{t}^{H}\right]} \geq 0 \\
B_{t}^{L} & =\frac{\beta\left[u_{h}\left(c_{t+1}^{L H}, c_{t}^{L}\right)-u_{h}\left(c_{t+1}^{L L}, c_{t}^{L}\right)\right]}{\left(\lambda_{t+1}^{L}+\hat{\lambda}_{t+1}^{L}\right) \mathbb{E}\left[\tilde{U}_{t} \mid \theta^{t-1}, \theta_{t}^{L}\right]} \geq 0 \\
A_{t}^{L} & =\beta \frac{\frac{v^{\prime}\left(y_{t}^{L} / \theta_{t}^{L}\right)}{\theta_{t}^{L}}-\frac{v^{\prime}\left(y_{t}^{L} / \theta_{t}^{H}\right)}{\theta_{t}^{H}}+\hat{U}_{t}^{L}-\mathbb{E}\left[\tilde{U}_{t} \mid \theta^{t-1}, \theta_{t}^{L}\right]}{q \pi_{t}\left(\theta_{t}^{L} \mid \theta_{t-1}\right)\left(\lambda_{t+1}^{L}+\hat{\lambda}_{t+1}^{L}\right) \mathbb{E}\left[\tilde{U}_{t} \mid \theta^{t-1}, \theta_{t}^{L}\right]} \geq 0 .
\end{aligned}
$$

Proceeding as in the proof of Proposition 3, the labor wedges can be represented as $\tau_{y, t}^{H}=$ $-\mu_{t+1}^{H} B_{t}^{H}$ and $\tau_{y, t}^{L}=\mu_{t} A_{t}^{L}-\mu_{t+1}^{L} B_{t}^{L}$. Note that the habit effects $B_{t}^{H}, B_{t}^{L}$ are exact analogies to the case with transitory shocks. The instantaneous labor distortion $A_{t}^{L}$ includes one additional term:

$$
\begin{aligned}
& \hat{U}_{t}^{L}-\mathbb{E}\left[\tilde{U}_{t} \mid \theta^{t-1}, \theta_{t}^{L}\right] \\
= & \beta \sum_{j} u_{h}\left(c_{t+1}^{L j}, c_{t}^{L}\right) \pi_{t+1}\left(\theta_{t+1}^{j} \mid \theta_{t}^{H}\right)-\beta \sum_{j} u_{h}\left(c_{t+1}^{L j}, c_{t}^{L}\right) \pi_{t+1}\left(\theta_{t+1}^{j} \mid \theta_{t}^{L}\right) \\
= & \beta\left[\pi_{t+1}\left(\theta_{t+1}^{H} \mid \theta_{t}^{H}\right)-\pi_{t+1}\left(\theta_{t+1}^{H} \mid \theta_{t}^{L}\right)\right]\left[u_{h}\left(c_{t+1}^{L H}, c_{t}^{L}\right)-u_{h}\left(c_{t+1}^{L L}, c_{t}^{L}\right)\right] \geq 0
\end{aligned}
$$

Savings wedges can be derived similarly to the proof of Proposition 4. For the high-skilled worker $(i=H)$ we define

$$
\begin{aligned}
D_{t}^{i} & =\frac{\mathbb{E}\left[\tilde{U}_{t+1} \mid \theta^{t-1}, \theta_{t}^{i}, \theta_{t+1}^{L}\right]-\mathbb{E}\left[\tilde{U}_{t+1} \mid \theta^{t-1}, \theta_{t}^{i}, \theta_{t+1}^{H}\right]}{\lambda_{t+1}^{i} \mathbb{E}\left[\tilde{U}_{t+1} \mid \theta^{t-1}, \theta_{t}^{i}\right]} \\
E_{t}^{i} & =\frac{q\left[u_{h}\left(c_{t+1}^{i H}, c_{t}^{H}\right)-u_{h}\left(c_{t+1}^{i L}, c_{t}^{i}\right)\right]}{\lambda_{t+1}^{i} \mathbb{E}\left[\tilde{U}_{t+1} \mid \theta^{t-1}, \theta_{t}^{i}\right]} \\
F_{t}^{i j} & =\frac{q\left[u_{h}\left(c_{t+2}^{i j H}, c_{t+1}^{i j}\right)-u_{h}\left(c_{t+2}^{i j L}, c_{t+1}^{i j}\right)\right]}{\lambda_{t+1}^{i} \mathbb{E}\left[\tilde{U}_{t+1} \mid \theta^{t-1}, \theta_{t}^{i}\right]}, \quad j=L, H,
\end{aligned}
$$

and obtain the savings wedge

$$
\tau_{s, t}^{i}=\mu_{t+1}^{i} D_{t}^{i}+\mu_{t+1}^{i} E_{t}^{i}+\sum_{j} \pi_{t+1}\left(\theta_{t+1}^{j} \mid \theta_{t}^{i}\right) \mu_{t+2}^{i j} F_{t}^{i j}
$$


This is again an exact analogy to the case with transitory shocks. For the low-skilled worker $(i=L)$ we replace $\lambda_{t+1}^{i}$ by the sum $\lambda_{t+1}^{L}+\hat{\lambda}_{t+1}^{L}$ in the definitions of $D_{t}^{i}, E_{t}^{i}, F_{t}^{i j}$, and we define

$$
\begin{aligned}
\hat{D}_{t}^{L} & =\frac{\sum_{j}\left[\pi_{t+1}\left(\theta_{t+1}^{j} \mid \theta_{t}^{L}\right)-\pi_{t+1}\left(\theta_{t+1}^{j} \mid \theta_{t}^{H}\right)\right] \mathbb{E}\left[\tilde{U}_{t+1} \mid \theta^{t-1}, \theta_{t}^{L}, \theta_{t+1}^{j}\right]}{\left(\lambda_{t+1}^{L}+\hat{\lambda}_{t+1}^{L}\right) \mathbb{E}\left[\tilde{U}_{t+1} \mid \theta^{t-1}, \theta_{t}^{L}\right]} \\
\hat{E}_{t}^{L} & =\frac{q \sum_{j} u_{h}\left(c_{t+1}^{L j}, c_{t}^{L}\right)\left[\pi_{t+1}\left(\theta_{t+1}^{j} \mid \theta_{t}^{H}\right)-\pi_{t+1}\left(\theta_{t+1}^{j} \mid \theta_{t}^{L}\right)\right]}{\left(\lambda_{t+1}^{L}+\hat{\lambda}_{t+1}^{L}\right) \mathbb{E}\left[\tilde{U}_{t+1} \mid \theta^{t-1}, \theta_{t}^{L}\right]}
\end{aligned}
$$

The savings wedge is then

$$
\tau_{s, t}^{L}=\mu_{t+1}^{L} D_{t}^{L}+\hat{\lambda}_{t+1}^{L} \hat{D}_{t}^{L}+\mu_{t+1}^{L} E_{t}^{L}+\hat{\lambda}_{t+1}^{L} \hat{E}_{t}^{L}+\sum_{j} \pi_{t+1}\left(\theta_{t+1}^{j} \mid \theta_{t}^{L}\right) \mu_{t+2}^{L j} F_{t}^{L j}
$$

The concavity/wealth effect is captured by the sum $\mu_{t+1}^{L} D_{t}^{L}+\hat{\lambda}_{t+1}^{L} \hat{D}_{t}^{L}$. Note that $\hat{D}_{t}^{L}$ is zero if $c_{t+1}^{L H}=c_{t+1}^{L L}$. Hence, even though the Lagrange multiplier $\mu_{t+1}^{L}$ does not show up directly, the part $\hat{\lambda}_{t+1}^{L} \hat{D}_{t}^{L}$ vanishes if $\mu_{t+1}^{L}=0$. If $\mu_{t+1}^{L}>0$, then due to concavity and $\pi_{t+1}\left(\theta_{t+1}^{L} \mid \theta_{t}^{L}\right)>$ $\pi_{t+1}\left(\theta_{t+1}^{L} \mid \theta_{t}^{H}\right)$, the term $\hat{\lambda}_{t+1}^{L} \hat{D}_{t}^{L}$ is positive, just like $\mu_{t+1}^{L} D_{t}^{L}$. The immediate habit effect consists of the terms $\mu_{t+1}^{L} E_{t}^{L}+\hat{\lambda}_{t+1}^{L} \hat{E}_{t}^{L}$. The term $\mu_{t+1}^{L} E_{t}^{L}$ is familiar and looks just like in the case of the high-skilled worker. The term $\hat{\lambda}_{t+1}^{L} \hat{E}_{t}^{L}$ goes in the same direction, since $\pi_{t+1}\left(\theta_{t+1}^{H} \mid \theta_{t}^{H}\right)>$ $\pi_{t+1}\left(\theta_{t+1}^{H} \mid \theta_{t}^{L}\right)$ and $u_{h}\left(c_{t+1}^{L H}, c_{t}^{L}\right)>u_{h}\left(c_{t+1}^{L L}, c_{t}^{L}\right)$ due to complementarity. Hence $\hat{\lambda}_{t+1}^{L} \hat{E}_{t}^{L}$ is also an immediate habit effect. Even though $\mu_{t+1}^{L}$ does not show up directly, we note that this term will be zero if $\mu_{t+1}^{L}=0$, or equivalently if $c_{t+1}^{L H}=c_{t+1}^{L L}$. Finally we have the subsequent habit effect, consisting of the terms $\mu_{t+2}^{L j} F_{t}^{L j}$ just like in the case of the high-skilled worker.

\section{References}

ABel, A. B. (1990): "Asset Prices under Habit Formation and Catching up with the Joneses," American Economic Review, 80(2), 38-42.

Abraham, A., S. Koenne, and N. Pavoni (2013): "Optimal Income Taxation with Asset Accumulation," European University Institute. Mimeo.

Albanesi, S., And C. Sleet (2006): "Dynamic Optimal Taxation with Private Information," Review of Economic Studies, 73(1), 1-30. 
Campbell, J. Y., and J. H. Cochrane (1999): "By Force of Habit: A Consumption-Based Explanation of Aggregate Stock Market Behavior," Journal of Political Economy, 107(2), $205-251$.

Carroll, C. D., J. Overland, And D. N. Weil (2000): "Saving and Growth with Habit Formation," American Economic Review, 90(3), 341-355.

Clark, A. E. (1999): "Are wages habit-forming? evidence from micro data," Journal of Economic Behavior \& Organization, 39(2), 179-200.

Constantinides, G. M. (1990): "Habit Formation: A Resolution of the Equity Premium Puzzle," Journal of Political Economy, 98(3), 519-43.

Cremer, H., P. De Donder, D. Maldonado, and P. Pestieau (2010): "Commodity Taxation under Habit Formation and Myopia," The BE Journal of Economic Analysis E Policy, 10(1).

Cremer, H., and F. Gahvari (1995a): "Uncertainty and optimal taxation: In defense of commodity taxes," Journal of Public Economics, 56(2), 291-310. (1995b): "Uncertainty, optimal taxation and the direct versus indirect tax controversy," The Economic Journal, pp. 1165-1179.

Cremer, H., And P. Pestieau (2011): "Myopia, redistribution and pensions," European Economic Review, 55(2), 165 - 175.

Diamond, P. A., and J. A. Mirrlees (1978): "A model of social insurance with variable retirement," Journal of Public Economics, 10(3), 295 - 336.

Diaz, A., J. Pijoan-Mas, and J. Rios-Rull (2003): "Precautionary savings and wealth distribution under habit formation preferences," Journal of Monetary Economics, 50(6), 12571291.

FARHi, E., And I. Werning (2013): "Insurance and taxation over the life cycle," The Review of Economic Studies, 80(2), 596-635.

Feldstein, M. (1973): "On the optimal progressivity of the income tax," Journal of Public Economics, 2(4), $357-376$. 
Fernandes, A., And C. Phelan (2000): "A recursive formulation for repeated agency with history dependence," Journal of Economic Theory, 91(2), 223-247.

Frederick, S., And G. Loewenstein (1999): "Hedonic Adaptation," in Well-being: The foundations of hedonic psychology, ed. by D. Kahneman, E. Diener, and N. Schwarz, pp. 302-329. Russell Sage Foundation Press.

Fuhrer, J. C. (2000): "Habit Formation in Consumption and Its Implications for MonetaryPolicy Models," The American Economic Review, 90(3), pp. 367-390.

Golosov, M., N. Kocherlakota, and A. Tsyvinski (2003): "Optimal Indirect and Capital Taxation," Review of Economic Studies, 70(3), 569-587.

Golosov, M., And A. Tsyvinski (2006): "Designing Optimal Disability Insurance: A Case for Asset Testing," Journal of Political Economy, 114(2), 257-279.

Gottardi, P., And N. Pavoni (2011): "Ramsey Asset Taxation under Asymmetric Information," European University Institute. Mimeo.

Grochulski, B., And N. Kocherlakota (2010): "Nonseparable preferences and optimal social security systems," Journal of Economic Theory, 145(6), 2055 - 2077.

Hansen, G. (1993): "The Cyclical and Secular Behaviour of the Labour Input: Comparing Efficiency Units and Hours Worked," Journal of Applied Econometrics, 8(1), 71-80.

Heathcote, J., K. Storesletten, and G. Violante (2012): "Consumption and labor supply with partial insurance: An analytical framework," Federal Reserve Bank of Minneapolis and New York University, Mimeo.

Helson, H. (1964): Adaptation-Level Theory. Harper \& Row New York.

Johnsen, T. H., and J. B. Donaldson (1985): "The Structure of Intertemporal Preferences under Uncertainty and Time Consistent Plans," Econometrica, 53(6), pp. 1451-1458.

KapickA, M. (2013): "Efficient Allocations in Dynamic Private Information Economies with Persistent Shocks: A First-Order Approach," The Review of Economic Studies, 80(3), 10271054 
Kocherlakota, N. R. (2005): "Zero Expected Wealth Taxes: A Mirrlees Approach to Dynamic Optimal Taxation," Econometrica, 73(5), 1587-1621.

Messinis, G. (1999): "Habit Formation and the Theory of Addiction," Journal of Economic Surveys, 13(4), 417-42.

MirrleEs, J. A. (1971): "An Exploration in the Theory of Optimum Income Taxation," Review of Economic Studies, 38(114), 175-208.

Phelan, C., And R. M. Townsend (1991): "Computing Multi-Period, InformationConstrained Optima," The Review of Economic Studies, 58(5), 853-881.

RavinA, E. (2007): "Habit Persistence and Keeping Up with the Joneses: Evidence from Micro Data," New York University. Mimeo.

Rogerson, W. P. (1985): "Repeated Moral Hazard," Econometrica, 53(1), 69-76.

Ryder, JR., H. E., ANd G. M. HeAl (1973): "Optimum Growth with Intertemporally Dependent Preferences," Review of Economic Studies, 40(1), 1-33.

Spear, S., And S. SRIVAstava (1987): "On repeated moral hazard with discounting," Review of Economic Studies, 54(4), 599-617.

Stern, N. (1982): "Optimum taxation with errors in administration," Journal of Public Economics, $17(2), 181-211$.

Stiglitz, J. E. (1982): "Self-selection and Pareto efficient taxation," Journal of Public Economics, $17(2), 213-240$.

Werning, I. (2011): "Nonlinear capital taxation," MIT. Mimeo. 